\title{
VALIDATION OF CRYOSAT-2 SIRAL SEA LEVEL DATA IN THE EASTERN CONTINENTAL SHELF OF THE GULF OF CADIZ (SPAIN)
}

\section{J. Gómez-Enri (1)(*) - S. Vignudelli (2) - P. Cipollini (3) - J. Coca (1) (4) - C.J. González (1)}

(1) University of Cadiz. Av. Republica Saharaui, s/n. 11510. Puerto Real (Cadiz). Spain. jesus.gomez@uca.es; carlosjose.gonzalez@uca.es.

(2) Institute of Biophysics, National Research Council. Via Moruzzi, 1. 56024. Pisa, Italy.vignudelli@pi.ibf.cnr.it.

(3) National Oceanography Centre. European Way, SO14 3ZH Southampton, United Kingdom.cipo@noc.ac.uk.

(4) University of Las Palmas. c/Juan de Quesada, 30. 35001. Las Palmas de Gran Canarias, Spain. josep.coca@uca.es.

\begin{abstract}
We present the validation of sea level measurements taken over the eastern shelf of the Gulf of Cadiz (southwestern Iberian Peninsula) by the European Space Agency CryoSat-2 satellite's SIRAL altimeter in SAR mode. Time series of sea level anomaly (SLA) at 20-Hz posting rate (corresponding to approximately $350 \mathrm{~m}$ along the satellite track) are compared against sea level measurements from two tide gauge stations located along the Spanish coast of the study area. Due to the long repeat cycle of CryoSat-2 (369 days), data selection is performed by including all the tracks falling in a radius of $50 \mathrm{~km}$ from the location of the tide gauge stations. Then, time series of SLA are formed during the observational time period (August 2010 - December 2014) by taking the altimeter measurements located at growing distances from the coast $(1,3,5$, $10,15$ and $20 \mathrm{~km})$ as well as around four isobaths $(10,25,50$ and $75 \mathrm{~m})$. The validation of AltiKa's SARAL altimeter 20-Hz data, using its two 35-day-repeat ground tracks available in the area is also presented. Overall, CryoSat-2 20-Hz SLAs selected in the coastal strip from 3 to $20 \mathrm{~km}$ agree well with data from the western station (Huelva) with rmse ranging from 11.4 to $6.4 \mathrm{~cm}$. The analysis at the eastern station (Bonanza) yields rmse ranging from 16.8 to $14.6 \mathrm{~cm}$. The comparisons made with CryoSat-2 20$\mathrm{Hz}$ SLAs are in agreement with the rmse estimated using AltiKa 20-Hz SLAs at distances to the coast higher than $5 \mathrm{~km}$, and much better in the $1-5$ coastal band. The differences in quantity of SAR mode data observed at the two stations and in their agreement with the tide gauges can be explained by (1) the more complex coastal morphology around Bonanza station with the altimetry tracks almost parallel to the coast; (2) the noisier hydrodynamics around Bonanza station due to the presence of the estuary mouth of the Guadalquivir River; and (3) residual (uncorrected) tidal signals in the Bonanza gauge record. We conclude that the quality of SAR altimetry is comparable or even slightly better than conventional altimetry, thus qualifying SAR data for exploitation in oceanographic studies and sea level monitoring. An example is the analysis made of the surface signal due to a heavy Guadalquivir River discharge event.
\end{abstract}

Keywords: satellite SAR altimetry, tide gauge, validation, applications

(*) Corresponding author 


\section{INTRODUCTION}

The launch of the European Space Agency (ESA) satellite CryoSat-2 carrying the Synthetic Aperture Radar (SAR) Interferometric Radar Altimeter (SIRAL, henceforth) in February 2010 marked a milestone in satellite altimetry as the first spaceborne instrument with SAR altimetry capability. Compared to conventional pulselimited altimetry, SAR altimetry, also known as delay-Doppler altimetry (Raney, 1998), has the potential to provide a better along-track resolution and a higher Signal-to-Noise ratio (SNR). The SIRAL instrument operates in one of three modes: SAR, SARinterferometric (SARin) and Low Rate Mode (LRM); the mode of operation is selected over different regions according to a Geographical Mode Mask (ESA-ESRIN, 2012). The SAR mode is enabled on sea-ice zones and some selected marine areas, including coastal zones (as the study area investigated in this work). The SARin mode is enabled over ice-sheet margins, small ice caps and mountain glaciers. Finally, the conventional LRM mode is enabled over the open oceans, continental ice sheets and all the land areas not covered by the other modes (ESA-ESRIN, 2012). ESA is generating and distributing CryoSat-2 Ocean Products derived from the LRM measurements, with the addition of Pseudo-LRM (PLRM) measurements over the SAR mode zones ${ }^{1}$. These products have now been comprehensively validated (Calafat et al., 2017) and confirm the value of CryoSat-2 for oceanography and climate studies.

The validation of SAR-mode observations over the various SAR-mode patches is ongoing. A global assessment has recently been carried out by Boy et al. (2017), but still there is scope for detailed regional and coastal validation studies, as in the coastal

\footnotetext{
${ }^{1}$ PLRM data are generated from SAR mode data in a way that yields waveforms conforming to the LRM echo model, and that can therefore be processed as the LRM waveforms, at the cost of higher level of speckle noise, i.e. lower measurement precision than conventional LRM.
} 
zone, SAR altimetry holds particular promise by virtue of its increased resolution and SNR. Some of those studies have appeared already: Fenoglio-Marc et al. (2015) analysed the quality of the geophysical parameters derived from SAR and LRM modes in the German Bight, while Passaro et al. (2016) have cross-calibrated CryoSat-2 SARmode height with Envisat reprocessed using coastal altimetry techniques in the Indonesian Seas. This paper aims at contributing to the validation of SAR altimetry data from CryoSat-2 by assessing sea level data in the coastal strip of the eastern shelf of the Gulf of Cadiz (Spain). The Gulf of Cadiz and the adjacent Strait of Gibraltar have been already used for the validation of coastal altimetry, by Caballero et al. (2014) for Envisat significant wave height (SWH), and by Gómez-Enri et al. (2016) for sea surface height (SSH) from Envisat and AltiKa, so this paper is complementary to those validation studies.

The validation of geophysical parameters retrieved from radar altimeter satellite missions (sea level, significant wave height and wind speed at the sea surface) is a common exercise that the altimetric community makes to assess the performances of the various altimeters and the suitability of the measurements for oceanographic applications. The quality of the retrieved parameters has been assessed since the beginning of the missions, from the NASA/CNES Topex-Poseidon (Picaut et al., 1995; Mitchum, 1998; Birol and Delebecque, 2014) and its successors Jason-1/2 (Ménard et al., 2003; Vincent et al., 2003; Woodworth et al., 2004; Bonnefond et al., 2011; Passaro et al., 2015; among others) to the ESA Envisat RA-2 (Faugere et al., 2006; Passaro et al., 2015; Gómez-Enri et al., 2016).

The specific objective of this paper is to validate time series of Sea Level Anomaly (SLA, i.e. the anomaly of the sea surface height with respect to its temporal 
mean) from CryoSat-2 SIRAL operating in SAR mode near the shore. The sea level data were obtained from an ESA web service (see section 3.1.1 for details) designed to process on line and on demand CryoSat-2 SAR data at a high posting rate $(20 \mathrm{~Hz}$, corresponding to approximately $350 \mathrm{~m}$ along the satellite track). We compare the satellite-derived time series of SLA with the water levels of two tide gauge stations (Huelva and Bonanza) located in the Spanish coast of the Gulf of Cadiz. The altimeter data at $20 \mathrm{~Hz}$ are selected considering the tracks available in a radius of $50 \mathrm{~km}$ from the location of the tide gauge stations, and forming time series for the analysed time period (August 2010 - December 2015) with the radar measurements located at growing distances $^{2}$ to the coast $(1,3,5,10,15$ and $20 \mathrm{~km})$ as well as around four isobaths $(10$, $25,50$ and $75 \mathrm{~m})$. The time series of altimeter data, one for each distance or isobath, are then compared against those from the in-situ stations.

The paper is organised as follows: the study area is presented in Section 2, followed by a description of the data sets (Section 3) and methods (Section 4). In Section 5, the validation of CryoSat-2 SIRAL SLA using in-situ data is shown at the six distances to the coast and four bottom depths mentioned above. We also included in this section the validation results of AltiKa SARAL 20-Hz data using the two tracks available in the area, and a study of the impact of a high-discharge event from the Guadalquivir River on the altimetric data. Section 6 summarises the main results and presents the conclusions.

\section{STUDY AREA}

\footnotetext{
2 "Distance to coast" in this study refers to distance of closest approach, as opposed to along-track distance
} 
The validation of CryoSat-2 SIRAL data was made over the eastern shelf of the Gulf of Cadiz (East_GoC hereinafter) (Figure 1). SIRAL operates in SAR mode in this area. East_GoC is located between the Iberian Peninsula and the Atlantic coast of Morocco connecting the North Atlantic Ocean and the Mediterranean Sea through the Strait of Gibraltar, and its continental shelf is around $50 \mathrm{~km}$ wide following the $200-\mathrm{m}$ isobath. The Guadalquivir River is the main tributary in the zone; other rivers worth of note are the Tinto-Odiel system and the Guadiana.

The surface circulation of the Gulf of Cadiz has been deeply analysed in the past. Its strong seasonality is linked to the offshore circulation (Peliz et al., 2007). García-Lafuente et al. (2006), and more recently, Criado-Aldeanueva et al. (2009) observed a mesoscale cyclonic cell in the continental shelf (East_GoC) during springsummer. In winter the eastward flow of this cell weakens or even disappears when the open sea circulation changes to cyclonic (Criado-Aldeanueva et al., 2009). A warm surface counter-current flows westward near the coast during the spring-summer seasons but reverses to eastward in late autumn-early winter (Stevenson, 1977; Relvas and Barton, 2002). The Guadalquivir River also plays its role in the surface circulation of the East_GoC. Sporadic but heavy freshwater discharges might contribute to the sea level at different time-scales as previously noted by Laiz et al. (2013) and Gómez-Enri et al. (2015). The latter used a new reprocessed altimeter gridded product with a finer spatio-temporal resolution $\left(1 / 16^{\circ} \times 1 / 16^{\circ}\right.$, daily), to analyse the effect of heavy discharges in the East_GoC adjacent to the river estuary. This product includes a bathymetry constraint and smaller correlation scales in the methodology developed to generate the gridded maps (Escudier et al., 2013). 
The study area has been also used in the past for the validation of conventional radar altimeter data near the shore. Gómez-Enri et al. (2012) and Laiz et al. (2013) used weekly maps of SLA from AVISO (Archiving, Validation and Interpretation of Satellite data in Oceanography) to validate time series of SLA, finding high and significant correlations $(r>0.85)$ with in-situ tide gauge sea level data at monthly time scales.

\section{DATA SETS}

\subsection{Altimeter data}

\subsubsection{CryoSat-2 SIRAL}

Data from CryoSat-2 SIRAL-Baseline B were provided by the European Space Agency (ESA) Grid Processing On-Demand (GPOD) SARvatore (SAR versatile altimetric toolkit for ocean research \& exploitation) service available at: https://gpod.eo.esa.int/. SARvatore-GPOD is based on the processing of CryoSat-2 SAR data from Level 1a data (also known as Full Bit Rate or FBR) up to L2 for application in open ocean, coastal zone and ice. The time period analysed spanned 4.5 years: August 2010 to December 2014. The SARvatore-GPOD service allows the user to configure the data processing at two processing levels: Level $1 \mathrm{~b}$, in which the multilooked radar waveforms are built, and Level 2 allowing the retrieval of the geophysical parameters. The CryoSat-2 data processing was restricted to the study area using a GPOD processing baseline tailored for coastal zones; the model retracking selected was the physically-based SAMOSA2 (Ray et al., 2015). This is an open ocean retracking method not optimised for coastal zone (but the processing from L1a to L1b is coastal-enhanced). The GPOD options selected for processing the data for this study were: at Level $1 \mathrm{~b}$ processing, apply the Hamming weighting window in azimuth, use 
exact Doppler Bean steering (beam-forming), FFT zero-padding and a wider stack subsetting to give a final radar receiving window size of 512 samples; for the Level 2 Processor, restrict the retracking to specific surfaces in all passes and apply a PTR width alpha parameter obtained from a Look-Up-Table. A complete description of all these options and their impact on the processing is in Dinardo (2013).

\subsubsection{AltiKa SARAL}

AltiKa SARAL was launched in February 2013 by the French CNES and the Indian ISRO. The altimeter is a pulse-limited instrument operating in Ka band (35.75 $\mathrm{GHz}$ ) providing a smaller footprint respect to other conventional pulse-limited missions in the $\mathrm{Ku}$ band around $13.6 \mathrm{GHz}$ (Jason series and Envisat). This is because of the bigger pulse bandwidth (480 MHz). This provides a better measurement accuracy and a better observation of coastal zones than Ku-band pulse-limited altimeters (CNES/ISRO, 2013).

The availability of AltiKa data in the area allows cross-checking of the results obtained with CryoSat-2 in terms of comparison against in-situ data. We analysed the two tracks available in the study area (Figure 1): ascending track A\#373 (close to Huelva station) and descending track D\#446 (close to Bonanza). The time period analysed was from March 2013 to April 2015. We obtained the SLA values at 40-Hz intervals from the GDR cycles available at AVISO ftp server: ftp://avisoftp.cnes.fr/AVISO/pub/saral/gdr_t/.

\subsection{In-situ tide gauge data}

Instantaneous water levels recorded at 5-minute intervals were obtained from two tide gauges available at East_GoC: Huelva and Bonanza (Figure 1). Huelva is 
located close to the Tinto-Odiel river system. Bonanza is at the mouth of the main tributary in the Gulf of Cadiz: The Guadalquivir River. The instruments are MIROS radar sensors measuring at $2 \mathrm{~Hz}$. Data are then averaged into 1-minute intervals and transmitted in real time. Then a final product at 5-minute intervals is generated and made available. The tide gauges are managed by the Spanish Puertos del Estado (http://www.puertos.es/) as part of their Red de Mareógrafos (REDMAR). REDMAR is integrated in the Permanent Service for Mean Sea Level (PSMSL) and Global Sea Level Observing System (GLOSS).

\subsection{Auxiliary altimeter datasets}

In this work we used the Technical University of Denmark DTU10 global tidal model (Cheng and Andersen, 2011) to de-tide both altimeter and in-situ data. We also used the DTU15 Mean Sea Surface (MSS) (Andersen and Knudsen, 2009) as the reference surface for the computation of the CryoSat-2 SLA. Both these auxiliary products were downloaded from the DTU ftp server (ftp://ftp.space.dtu.dk).

The bathymetry in the study area was extracted from the Bay of Biscay - Iberian Coast grid from EMODnet (European Marine Observation and Data Network, http://www.emodnet-hydrography.eu/). The coastline information was obtained from the Global Self-consistent Hierarchical High-resolution Shorelines (Wessel and Smith 1996) version 2.3.3 (GSHHS, http://www.ngdc.noaa.gov/mgg/shorelines/gshhs.html).

The atmospheric effects (high frequency winds and atmospheric pressure with periods lower than 20 days and the inverted barometer correction (Carrère and Lyard, 2003)) were corrected using the Dynamic Atmospheric Correction (DAC, henceforth). DAC is computed with the high-resolution two-dimensional barotropic model "Modèle 
aux Ondes de Gravité - 2 Dimensions" (MOG2D). The model is forced using the atmospheric pressure and winds from the European Centre for Medium-range Weather Forecasts (ECMWF) database. DAC is provided by AVISO in regular 6-hourly gridded maps (http://aviso.altimetry.fr/index.php?id=1278).

\subsection{River runoff}

Daily averages of river discharge $\left(Q_{d}\right)$ were downloaded from the Automatic Hydrological Information System hosted by the Spanish Minister of Agriculture, Food and Environment (http://www.chguadalquivir.es/saih). We selected the data from the Alcala del Río dam station which is the nearest to the estuary mouth (see Figure 1).

\section{METHODOLOGY}

\subsection{Time series of Sea Level Anomalies}

\subsubsection{CryoSat-2 SIRAL}

The satellite-derived SLA was obtained along the satellite tracks surrounding the tide gauges. We considered only the track segments in a radius of $50 \mathrm{~km}$ from the tide gauges during the analysed time period (Figure 1). High rate 20-Hz SLA (measurements along the track spaced about $350 \mathrm{~m}$ ) was calculated following:

$$
\text { Cryo_SLA }=\text { Orbit }- \text { Range }- \text { Range_corrections }- \text { Geophysical_corrections }- \text { MSS }
$$

where Orbit (also known as Altitude) gives the distance between the satellite's centre of mass and the reference surface (ellipsoid WGS84). Range is the retracked distance between the instrument and the mean reflected sea level, output by the SAMOSA2 
retracker (Ray et al., 2014; Fenoglio_Marc et al., 2015). Range_corrections include dry and wet tropospheric effects (from ECMWF models), ionospheric correction (Global Ionospheric Maps from JPL when available and Bent model (Bent et al., 1975) if not), while Geophysical_corrections include the atmospheric correction from DAC, geocentric pole tide and tidal correction (Geocentric Ocean Tide). The atmospheric correction was obtained interpolating the regular 6-hourly gridded maps to the alongtrack $20-\mathrm{Hz}$ positions along the analysed time period. The tidal correction is the sum of three terms: Ocean, loading and solid Earth tides. Ocean and loading tides were obtained using the routines available in DTU for the time and position of every altimeter data point. For the solid Earth tide, we used Cartwright and Ray (1990) from GPOD. Regarding the MSS, we interpolated the global DTU15 (Andersen and Knudsen, 2009; Andersen, 2010) to the altimeter measurement positions.

The only correction not available was the sea state bias (SSB). For SAR mode altimetry no broadly accepted models are currently available for this correction, so as a first approximation we subtracted from Range a 5\% of the significant wave height, following Fenoglio-Marc et al. (2015).

\subsubsection{AltiKa SARAL}

High rate 40-Hz SLA (Alti_SLA) was obtained following Eq. (1). We then averaged over 2 consecutive along-track $40-\mathrm{Hz}$ SLA measurements in order to obtain time series with the same posting rate $(20-\mathrm{Hz})$ as in CryoSat-2.

\subsubsection{Tide gauges}

The water levels provided at 5-minute time intervals were interpolated to the altimeter data times. SLA was obtained following: 


$$
\text { Ins_SLA }=\text { Water_Level }-D A C-O c e a n \_T i d e
$$

where Water_Level is the interpolated measurement; DAC was applied in the same way as to altimeter data, i.e the correction was estimated by interpolating the $D A C$ maps to the times and position of the tide gauge interpolated data. Finally, the Ocean_Tide was initially obtained from the DTU10 model as to altimeter data.

Figure 2 shows the time series of sea level anomalies at Huelva (Fig. 2.a) and Bonanza (Fig. 2.b) during the study time period. The sea level ranges between -30 and $30 \mathrm{~cm}$ at Huelva, while at Bonanza the range is larger. Bonanza has also a higher standard deviation of the 5-minute corrected time series $(18 \mathrm{~cm})$ than Huelva $(8 \mathrm{~cm})$. The peaks observed in Figure 2 in the sea level at Bonanza are partly related to strong freshwater Guadalquivir River discharges, but the presence of a quasi-periodic modulation with a period of $\sim 28$ days points clearly to a tidal residual caused by the incomplete removal of the tidal signal. Therefore, we assessed the performance of DTU10 in the study area, by comparing the DTU10 main constituents with those obtained from the harmonic analysis made by Puertos del Estado at the two tide gauge locations. We estimated the RMS of the differences between the main constituents and the Root Sum Square (RSS) as in Oreiro et al. (2014). The RSS is $2.4 \mathrm{~cm}$ at Huelva and $14 \mathrm{~cm}$ at Bonanza. This indicates that DTU10 is a good tidal model at Huelva, but might not be a good choice to de-tide the water levels at Bonanza. We therefore de-tided the time series at Bonanza using the prediction from the experimental harmonic parameters with up to 35 constituents. The residual water levels are shown in Fig. 2.c. The standard deviation of the time series at Bonanza drops from 18 to $11 \mathrm{~cm}$ and the 28 day residual signal appears to be much reduced (but, not totally removed, which is important for the discussion in section 6). Based on these results we have chosen to de- 
tide the time series by using the DTU10 model for the Huelva tide gauge, and the harmonic analysis components for the Bonanza tide gauge.

\subsubsection{Altimeter data selection}

Time series of CryoSat- 2 data were built considering the distance to the coast and the bathymetry of the study area. We first extracted 6 time series at distances of 1 , $3,5,10,15$ and $20 \mathrm{~km}$ to the GSHHS coastline, by taking, for each CryoSat-2 overpass, the measurement at the closest $20-\mathrm{Hz}$ position to the selected distance. As mentioned, the maximum distance to the TG locations was $50 \mathrm{~km}$. These time series were then used for comparison against in-situ data. In addition, we also created time series based on selected bathymetric depths, by taking the measurement at the closest $20-\mathrm{Hz}$ position to the depths of $10,25,50$ and $75 \mathrm{~m}$.

We performed a data screening to the altimeter time series in two steps: (1) Only SLA values inside the range [-1.5 1.5$] \mathrm{m}$ were retained; and (ii) all the values outside the median \pm 3 times the standard deviation of the SLA time series were considered as outliers and discarded. The concomitant time series of Cryo_SLA at different distances to the coast and depths were finally compared with Ins_SLA at both stations (Huelva and Bonanza). We estimated the root mean square error (rmse) between the altimeter (CryoSat-2 and AltiKa) and the tide gauge SLA time series.

\section{RESULTS}

\subsection{Verification of CryoSat-2 SLA noise}

The high-frequency Cryo_SLA along-track noise was checked by selecting the closest tracks to the tide gauges (one ascending and one descending) and computing the 
absolute value of the difference between two consecutive 20-Hz SLA measurements along the tracks (Abs_Diff_SLA). Following Passaro et al. (2014), this parameter gives a local estimate of the noise level of the SLA along the tracks selected, allowing an assessment of the quality of the data as a function of distance from the coast.

The absolute values of the SLA differences are shown in Figure 3 for the two CryoSat-2 overpasses closest to the Huelva station (one descending pass, i.e. North to South, and one ascending). The two overpasses considered show SLA differences below $15 \mathrm{~cm}$ along most of their tracks, with the exception of the portion of the track closer to land, where bigger values are observed at along-track distances to the coast of $4.5 \mathrm{~km}$ and less for the ascending pass, and only $1.3 \mathrm{~km}$ and less for the descending pass. The orientation of the passes with respect to the land might explain this difference: the orientation of the descending pass is closer to the perpendicular to the coastline, so less contamination in the SAR footprint area is expected in the $0-5 \mathrm{~km}$ range. The corresponding results obtained for the two passes close to Bonanza station (Figure 4) show relatively small values of $A b s \_D i f f \_S L A$ in the ocean/land transition (both tracks) but much bigger values around the crossover point near the Guadalquivir estuary mouth and in front of the town of Chipiona (see Fig. 1.b). The short $(\sim 2.2 \mathrm{~km})$ distance to the coast in the across-track direction near the crossover could explain the noisier data, owing to coastal and land reflections that contaminate the radar waveforms, and making the retrieval of accurate estimates of the sea level less precise. The contamination is clearly seen in the radargrams of the power echoes along the analysed track segments of the descending (Fig. 4.d) and ascending (Fig. 4.e) tracks. The position of the leading edge (and hence the tracking point used to estimate the sea level) is highly variable in the vicinity to the land in front of Chipiona around $\left[36.72-36.76^{\circ} \mathrm{N}\right]$. We also observed 
bigger values of $A b s_{-} D i f f \_S L A$ in the descending track at about $\left[36.81^{\circ}-36.83^{\circ}\right]$ latitude North. The waveforms in the track segment north of $36.8^{\circ}$ also show a distinct second peak in the tail of the waveform which might be due to calm water reflections from the Guadalquivir River and flooded areas near its mouth.

\subsection{CryoSat-2 SLA comparisons against in-situ data}

Figure 5 shows the position of the CryoSat-2 20-Hz data used at all the (alongtrack) distances to the land considered around Huelva (Fig. 5.a) and Bonanza (Fig. 5.b), respectively. These are the six time series of altimeter data. At each location the colour indicates the relative differences between Cryo_SLA and Ins_SLA (after the screening was performed). As mentioned, the $20-\mathrm{Hz}$ radar measurements selected are at a maximum radius to the tide gauges of $50 \mathrm{~km}$. The SLA difference values around the Huelva tide gauge are relatively small in magnitude except for the coastal area at the western end of the region. Differences altimetry - tide gauge for Bonanza are comparatively noisier.

Table 1 gives the comparison of Cryo_SLA and Ins_SLA at Huelva and Bonanza tide gauge stations in terms of rmse, and initial/final number of measurements used to estimate it. The rmse is reduced by $30 \%$ or more at Huelva station w.r.t. Bonanza, at distances to the land from 3 to $20 \mathrm{~km}$. At $1 \mathrm{~km}$ the comparison is poor, with high ( $>24$ $\mathrm{cm})$ rmse in both cases, due to the proximity of the radar measurements to the land. We also included in Table 1 the initial/final number of radar measurements used in the comparison against the tide gauges and the percentage of valid data used to estimate the rmse. This percentage is higher at Huelva station (indicating that fewer data are rejected in the data screening) and greater or equal than $95 \%$ for all distances greater or equal 
than $3 \mathrm{~km}$, which is a satisfactory result. For Bonanza, a larger percentage of outliers are found in the time series, and this, combined with the higher rmse, points at a particularly challenging area for the altimetry/tide gauge comparison. A contribution to the higher rmse at Bonanza might be due to shorter decorrelation scales for the oceanic signals, caused by the more complex coastal morphology w.r.t. Huelva. As the altimetric points around Bonanza form two distinct clusters (Figure 5.b) and the southern cluster is separated from the Bonanza tide gauge by a reef (Piedra Salmedina) in front of the town of Chipiona, we also estimated the rmse at Bonanza taking only the altimeter data from the northern cluster (i.e. north of latitude $36.63^{\circ} \mathrm{N}$ ), to check whether this would result into a better match with the tide gauge data. The results are shown in Table 1. Significant improvements (in terms of smaller rmse) are observed only at $1 \mathrm{~km}$ distance to the coast (at the cost of a substantial reduction in the number of valid points); elsewhere the results are comparable to those using both clusters, and remain significantly worse that those observed at Huelva.

Finally, we repeated the analysis by selecting the altimeter data by depth, as explained in subsection 4.1.4. We created CryoSat-2 20-Hz and in-situ time series considering four bathymetric depths: 10, 25, 50 and $75 \mathrm{~m}$. The rmse are shown in Table 2 and confirm a lower error as deeper bathymetries are considered (Huelva).

We analysed the effect of the noise in the CryoSat-2 radar measurements by recomputing the rmse w.r.t. the tide gauge data when the altimetric SLAs are averaged over 2, 4, 10 and 20 consecutive along-track 20-Hz measurements, centred at the 6 distances to the coast considered. These averaging correspond to $10-\mathrm{Hz}, 5-\mathrm{Hz}, 2-\mathrm{Hz}$ and $1-\mathrm{Hz}$ posting rates. The results are shown in Table 3. Averaging reduces significantly the rmse only in the distance band closer to the coast $(1 \mathrm{~km})$, especially at Huelva. This 
suggests that, at distances greater than $2 \mathrm{~km}$, the mismatch between altimetric and tide gauge measurements is mainly due to processes other than land contamination. These processes can be oceanographic processes (currents and residual tides, not completely removed by the tidal model) or residual long-wavelength errors in the altimeter orbit and corrections. The time series of Cryo_SLA and Ins_SLA used to estimate the rmse presented in Table 3 are shown in Figure 6, for both the original time series $(20-\mathrm{Hz})$ and the 20-points average $(1-\mathrm{Hz})$, and for a distance to the coast of $1 \mathrm{~km}(6 . \mathrm{a}$ and $6 . \mathrm{b}$ for Huelva and Bonanza, respectively) and $20 \mathrm{~km}$ (6.c and 6.d). Some of the peaks found in Cryo_SLA in the original dataset at a $1-\mathrm{km}$ distance are smoothed after the along-track averaging, especially at Huelva, and that results in the strong reduction observed in rmse from 29.3 to $11.7 \mathrm{~cm}$ (Table 3). The range of variation of in-situ data is bigger at Bonanza than at Huelva (as already shown in Figure 2). This, in addition to currents and residual tidal signal mentioned above, can be partly due in this particular location also to the complex hydrodynamic processes at the mouth of the Guadalquivir River estuary.

\subsection{AltiKa SLA comparisons against in-situ data}

Table 4 gives the rmse between CryoSat-2 / AltiKa and the tide gauges at a 20$\mathrm{Hz}$ posting rate. The results show the superiority of CryoSat-2 respect to AltiKa for ascending track $\# 0373$ at $5 \mathrm{~km}$ to the shore (Huelva station). AltiKa gives smaller rmse at distances higher than $5 \mathrm{~km}$, consistent with the well-known excellent radiometric performance of this satellite when land contamination can be excluded. The percentage of used data is, instead, smaller in AltiKa. No valid data are available for AltiKa (descending track \#0446) in the $10 \mathrm{~km}$ coastal band (Bonanza station). The location of the tracks respect to the tide gauge stations is shown in Fig. 1.b. A\#0373 is close to the Huelva station (minimum distance of $2 \mathrm{~km}$ ). This is not the case of D\#0446, which is at 
a minimum distance (perpendicular to the along-track direction) of $30 \mathrm{~km}$ to the Bonanza tide gauge. This could explain some of the differences found between in-situ and AltiKa data in this track.

\subsection{Sea level variability in the estuary mouth of the Guadalquivir River}

We analysed the capability of CryoSat-2 to detect the sea level variations due to the effect of strong river discharges in the adjacent continental shelf of the Guadalquivir River estuary mouth. The freshwater will reduce the salinity levels in the surface layer during these episodes as reported by González-Ortegón and Drake (2012), GonzálezOrtegón et al. (2010) and Navarro et al. (2012), resulting into a bulge in sea level. The elevation of the sea level in the continental shelf due to freshwater discharges has been confirmed with high resolution re-processed daily gridded maps of SLA (Gómez-Enri et al., 2015). We selected the heaviest river discharges during the analysed time period. The Guadalquivir River is said to be in extreme/exceptional conditions when the daily averages of $Q_{d}$ is bigger than $400 \mathrm{~m}^{3} / \mathrm{s}$ (Díez-Minguito et al. 2012). We observed only 5 time periods (over the duration of the time period analysed) with at least 3 consecutive days in extreme/exceptional conditions. Period 1: 42 days $\left(7^{\text {th }}\right.$ December $2010-17^{\text {th }}$ January 2011); Period 2: 7 days $\left(16^{\text {th }}-22^{\text {nd }}\right.$ February 2011); Period $3: 6$ days $\left(5^{\text {th }}-12^{\text {th }}\right.$ November 2012); Period 4: 48 days ( $1^{\text {st }}$ March - 20 $0^{\text {th }}$ April 2013; and Period 5: 8 days $\left(10^{\text {th }}-17^{\text {th }}\right.$ February 2014). A few CryoSat-2 tracks in the adjacent shelf of the estuary mouth were observed in three of these time windows: Periods 1, 2 and 4 . We also looked into the availability of optical RGB MODIS (Moderate Resolution Imaging Spectrometer) images (Terra) in the area from AERONET (http://lancemodis.eosdis.nasa.gov/imagery/subsets/?project=aeronet). We only found in the RGB images one day in Period 1 ( $4^{\text {th }}$ January 2011) with cloud-free conditions. The closest 
CryoSat-2 track (descending) to the estuary mouth (Fig. 7.b) was on $1^{\text {st }}$ January 2011 (daily $Q_{d}=1810.36 \mathrm{~m}^{3} / \mathrm{s}$ ), which corresponded to absolute orbit \#3884. The along-track 20-Hz SLA is shown in Fig. 7.a. We observe a 10-cm bulge in sea level centred around $36.7^{\circ} \mathrm{N}$ over the continental shelf that is consistent with the heavy freshwater discharge observed in the previous days to the altimeter measurements (Fig. 7.c). The RGB image (Fig. 7.b) shows the stronger turbidity plume in the adjacent continental shelf due to the river discharge, and a relatively larger area where the plume from the heavy discharge in previous days (see Fig. 7.c) appears to have mixed with the surrounding waters. We also examined the same track segment used in Figure 7 repeated over the 369-day CryoSat-2 orbit cycle during the analysed time period. Figure 8 shows the raw $20-\mathrm{Hz}$ SLA (Figure 8.a) and smoothed (running mean of 5 20-Hz measurements) SLA (Figure 8.b) for absolute orbits \#3884 (01/01/2011) - $9228(04 / 01 / 2012)$ - $14572(06 / 01 / 2013)$ and 19916 (09/01/2014). The highest sea level elevation, and the only bulging shape, was observed in the track segment corresponding to the only date with heavy river discharge (see the $Q_{d}$ in the figure during the dates analysed).

\section{DISCUSSION AND CONCLUDING REMARKS}

The overall objective of this paper was to carry out a validation of the state-ofthe-art CryoSat-2 data in SAR mode in the Gulf of Cadiz, which are available via the SARvatore processor on GPOD. We have assessed the quality of the product by comparing altimetry measurements with those collected by tide gauges and by conventional altimetry from AltiKa. The final purpose was to demonstrate that SAR altimetry was at least as good as conventional altimetry, if not better, and of a quality that allows meaningful application to oceanography and sea level monitoring. 
For the comparisons between CryoSat-2 altimeter and in-situ data we have chosen two locations relatively close $(\sim 60 \mathrm{~km})$ to each other, Huelva and Bonanza, but where the coastal morphology and the impact of river runoff is substantially different. Around Huelva there is a very simple coastline, as a first approximation oriented E to W and therefore nearly orthogonal to the CryoSat-2 tracks, with the presence of only minor river systems. Conversely, Bonanza sits in the estuary of a major river, featuring significantly high-runoff events, the coastal morphology is more complicated (even for the presence of low-lying flooded areas close to the river mouth, which generate bright returns in the altimetric signal as noted in 5.2), and the orientation of the coast is more parallel to the altimetry tracks, i.e. not particularly advantageous for SAR altimetry.

The difference in sea level variability between the two sites is apparent from the standard deviation observed in the 5-minute time series of the two tide gauges ( 8 and 18 $\mathrm{cm}$ for Huelva and Bonanza, respectively). This noisier hydrodynamics at the estuary mouth of the Guadalquivir River further complicates the comparison between groundtruth and satellite data and explains large part of the difference found between CryoSat2 data and the Bonanza tide gauge measurements.

Given the above, it is not surprising that the two sites gave rather different results in terms of magnitude of rmse between altimetry and tide gauge measurements. CryoSat-2 20-Hz SLA data selected in the coastal strip from 3 to $20 \mathrm{~km}$ agree well when compared with the Huelva in-situ station (rmse ranging between 11.4 and $6.4 \mathrm{~cm}$ ). This is not the case of the results obtained using Bonanza station (rmse greater than 17 $\mathrm{cm})$. 
The poorer quality of the CryoSat-2 measurements found in the SLA time series built at $1-\mathrm{km}$ distance to the coast for both stations is due to the corruption of the altimeter waveforms by land or bright targets at the coast, which decreases the quality of the geophysical parameters retrieved to estimate the SLA (range and significant wave height, in turn needed for the first-order estimate of the SSB used here). The effect of the land contamination over radar altimeter waveforms has been a matter of deep investigation in the coastal altimetry community (Vignudelli et al., 2011, and references therein). Figure 9 shows the radargrams of the waveforms selected to build the time series and estimate the rmse at Huelva at distances to the coast of $1 \mathrm{~km}$ (Fig. 9.a) and 20 km (Fig. 9.b). The typical sharper CryoSat-2 SAR ocean-like waveforms are more evident far from the coast. The waveforms at $1 \mathrm{~km}$ are much noisier with a less evident leading edge. This complicates their retracking and hence compromises the quality of the geophysical parameters. The result using CryoSat-2 20-Hz measurements at $1 \mathrm{Km}$ can be improved with some smoothing (as shown in Table 3) but only for Huelva; for Bonanza the higher rmse is only very marginally damped by smoothing, indicating that the differences are due mainly to the intrinsic variability at the tide gauge. At distances from the coast of $3 \mathrm{~km}$ or more, the results for Huelva are only slightly sensitive to smoothing.

The figures for CryoSat- 2 at the $1-5 \mathrm{~km}$ coastal band are much better than the rmse obtained using AltiKa $(20 \mathrm{~Hz})$. This is a satisfactory result for SAR altimetry, showing its good performance in this area.

In the eastern part of the study region around Bonanza, even if the intrinsic variability at the tide gauge prevents a satisfactory comparison of the time series, we 
have shown in 5.4 that altimetry can still capture the surface signal due to a large runoff event, and therefore maintain some usefulness.

In summary, in this paper we have attempted a thorough validation of the new SAR mode provided by CryoSat- 2 in the eastern continental shelf of the Gulf of Cadiz (Spain). The results are strongly dependent on the particular study site. In a site such as Bonanza, where the variability is dominated by river signals, the orientation of the altimetry track is less than ideal, the agreement of altimetry and tide gauge is unsatisfactory, both for SAR and conventional altimetry from AltiKa, even after we use a local harmonic analysis for removing the tidal signal in the gauge time series. However, even in these unfavourable circumstances we have shown that SAR altimetry from CryoSat-2 captures the river plume surface signal following a large runoff event. Instead, in the much more favourable case of Huelva, where the tracks are almost perpendicular to a simple coast, unaffected by major river discharges, and the DTU10 model does a satisfactory job to remove the tidal signals, the time series of CryoSat- 2 in SAR mode at $20 \mathrm{~Hz}$ match the tide gauge time series better than AltiKa at $5 \mathrm{~km}$ to the shore. CryoSat-2 performs almost as well as AltiKa from $10 \mathrm{~km}$ outwards. These figures validate this product for the study of the variability of sea level and circulation in the area around Huelva. The degradation of the results shorewards of $3 \mathrm{~km}$ from the coast calls for the development of dedicated retracking technique to limit the impact on waveforms due to land and bright target in the SAR footprint.

We conclude by noting that this work has contributed to assess the improvement due to full SAR processing closer to the coast, where we expect better capabilities than conventional altimetry. The original validation methodology proposed here can be replicated in other coastal regions in order to quantify the improvement in terms of 
quality and quantity of data as a function of distance from the coast and orientation of the tracks.

\section{ACKNOWLEDGMENTS}

This work was made in the frame of the ALCOVA Project (CTM2012-37839) funded by the Spanish Ministerio de Economía y Competitividad and FEDER. P. Cipollini has been partially supported by the Natural Environment Research Council (NERC) National Capability funding. Authors thank the National Space Institute of Technical University of Denmark (http://www.space.dtu.dk/) for providing the DTU13/DTU15 Mean Sea Surface and DTU10 tide model. Tide gauge data were extracted from the Spanish Puertos del Estado. The bathymetric Bay of Biscay - Iberian Coast grid products have been downloaded from the EMODnet Bathymetry portal. Authors also thank ESA for providing the CryoSat-2 SIRAL SARvatore GPOD data. 


\section{REFERENCES}

Andersen, O. B., 2010. The DTU10 Gravity field and Mean sea surface, Second international symposium of the gravity field of the Earth (IGFS2), Fairbanks, Alaska. Oral presentation.

Andersen, O. B., Knudsen, P., 2009. The DNSC08 mean sea surface and mean dynamic topography. J. Geophys. Res.-Oceans, 114, 1-12. http://dx.doi.org/10.1029/2008JC005179.

Bent R. B., Llewellyn, S., Nesterczuk, G. Schmid, P., 1975. The development of a highly-successful worldwide empirical ionospheric model and its use in certain aspects of space communications and world-wide total electron content investigations. In: Goodman JM (ed) Effect of the Ionosphere on Space Systems and Communications (Proceedings), January 20-22, U. S. Government Printing Office, Washington, D.C., Stock\#008-051-00064-0, 13-28, Arlington, VA.

Birol, F., Delebecque, C., 2014. Using high sampling rate $(10 / 20 \mathrm{~Hz})$ altimeter data for the observation of coastal surface currents: A case study over the northwestern Mediterranean Sea. J. Mar. Syst., 129, 318-333. doi: http://dx.doi.org/10.1016/j.jmarsys.2013.07.009.

Bonnefond, P., Haines, B. J., Watson, C., 2011. In situ Absolute Calibration and Validation: A Link from Coastal to Open-Ocean Altimetry. In: Vignudelli, S., Kostianoy, A., Cipollini, P., Benveniste, J. (Eds.), Coastal Altimetry. Berlin, Germany: Springer-Verlag, 259-296. http://dx.doi.org/10.1007/978-3-642-127960_11.

Boy, F., Desjonquères, J. D., Picot, N., Moreau, T., Raynal, M., 2017. CryoSat-2 SARMode Over Oceans: Processing Methods, Global Assessment, and Benefits. IEEE T. Geosci. Remote, $55 \quad$ (1), 148-158. http://dx.doi.org/10.1109/TGRS.2016.2601958.

Caballero, I., Gómez-Enri, J. Cipollini, P., Navarro, G., 2014. Validation of high spatial resolution wave data from Envisat RA-2 altimeter in the Gulf of Cádiz, IEEE Geoscience and Remote Sensing Letters, 11 (1), 371-375. http://dx.doi.org/10.1109/LGRS.2013.2261048.

Calafat, F., Cipollini, P., Bouffard, J., Snaith, H. Féménias, P., 2017. Evaluation of new CryoSat-2 products over the ocean, Remote Sensing of Environment, 191, 131144. http://dx.doi.org/10.1016/j.rse.2017.01.009.

Carrère, L., Lyard, F., 2003. Modeling the barotropic response of the global ocean to atmospheric wind and pressure forcing - comparisons with observations. Geophys. Res. Lett. 30 (6), 1275, pp.4. http://dx.doi.org/10.1029/2002GL016473.

Cartwright, D. E., Ray, R. D., 1990. Oceanic tides from Geosat altimetry. J. Geophys. Res.-Oceans, 95, 3069-3090. http://dx.doi.org/10.1029/JC095iC03p03069. 
CNES/ISRO, 2013. SARAL AltiKa Products Handbook. Available at: https://www.aviso.altimetry.fr/fileadmin/documents/data/tools/SARAL_Altika_pro ducts_handbook.pdf.

Criado-Aldeanueva, F., García-Lafuente, J., Navarro, G., Ruiz, J., 2009. Seasonal and interannual variability of the surface circulation in the eastern Gulf of Cadiz (SW Iberia). J. Geophys. Res. 114, C01011, pp. 11. http://dx.doi.org/10.1029/2008JC005069.

Cheng, Y., Andersen, O. B., 2011. Multimission empirical ocean tide modelling for shallow waters and polar seas. J. Geophys. Res., 116, C11001, pp. 11. http://dx.doi.org/10.1029/2011JC007172.

Díez-Minguito, M., Baquerizo, A., Ortega-Sánchez, M., Navarro, G., Losada, M. A. 2012. Tide transformation in the Guadalquivir estuary (SW Spain) and processbased zonation. J. Geophys. Res. 117, C03019, pp. 14. http://dx.doi.org/10.1029/2011JC007344.

Dinardo, S., 2013. Guidelines for the SAR (Delay-Doppler) L1b Processing. European Space Agency: Paris, France.

Escudier, R., J. Bouffard, A. Pascual, P. M. Poulain, and M. I. Pujol (2013): Improvement of coastal and mesoscale observation from space: Application to the northwestern Mediterranean Sea, Geophys. Res. Lett. 40, 2148-2153, doi: 10.1002/grl.50324.

ESRIN-ESA, 2012. Cryosat Product Handbook, European Space Agency, Paris, France. Available at: http://emits.sso.esa.int/emits-doc/ESRIN/7158/CryoSat-PHB17apr2012.pdf.

Faugere, J., Dorandeu, J., Lefèvre, F., Féménias, P., 2006. Envisat ocean altimetry performance assessment and cross-calibration. Sensors, 6, 100-130.

Fenoglio-Marc L., Dinardo, S., Scharroo, R., Roland, A., Dutour Sikiric, M., Lucas, B., Becker, M., Benveniste, J., Weiss, R., 2015. The German Bight: A validation of Cryosat-2 altimeter data in SAR mode. Adv. Space Res. 55, 2641-2656. http://dx.doi.org/10.1016/j.asr.2015.02.014.

García-Lafuente, J., Delgado, J., Criado-Aldeanueva, F., Bruno, M., del Rio, J., Vargas, J. M., 2006. Water mass circulation on the continental shelf of the Gulf of Cadiz. Deep Sea Res. Part II-Topical Studies in Oceanography 53, 1182-1197. http://dx.doi.org/10.1016/J.DSR2.2006.04.011.

Gómez-Enri, J., Aboitiz, A., Tejedor, B., Villares, P., 2012. Seasonal and interannual variability in the Gulf of Cadiz: Validation of gridded altimeter products. Est. Coast. and Shelf Sci. 96, 114-121. http://dx.doi.org/10.1016/J.ECSS.2011.10.013. 
Gómez-Enri, J., Cipollini, P., Passaro, M., Vignudelli, S., Tejedor, B., Coca, J., 2016. Coastal altimetry products in the Strait of Gibraltar. IEEE T. Geosci. Remote, 54, 9, 5455-5466. http://dx.doi.org/10.1109/TGRS.2016.2565472.

Gómez-Enri, J., Escudier, R., Pascual, A., Mañanes, R., 2015. Heavy Guadalquivir River discharge detection with satellite altimetry: The case of the eastern continental shelf of the Gulf of Cadiz (Iberian Peninsula). Adv. Space Res. 55, 1590-1603. http://dx.doi.org/10.1016/j.asr.2014.12.039.

González-Ortegón, E., Drake, P., 2012. Effects of freshwater inputs on the lower trophic levels of a temperate estuary: physical, physiological or trophic forcing? Aq. Sci. 74, 455-469. http://dx.doi.org/10.1007/S00027-011-0240-5.

González-Ortegón, E., Subida, M. D., Cuesta, J. A., Arias, A. M., Fernández-Delgado, C., Drake, P., 2010. The impact of extreme turbidity events on the nursery function of a temperate European estuary with regulated freshwater inflow. Est., Coast. and Shelf Sci. 87, 311-324. http://dx.doi.org/10.1016/J.ECSS.2010.01.013.

Laiz, I., Gómez-Enri, J., Tejedor, B., Aboitiz, A., Villares, P., 2013. Seasonal sea level variations in the gulf of Cadiz continental shelf from in-situ measurements and satellite altimetry. Cont. Shelf Res., 53, 77-88. http://dx.doi.org/10.1016/J.CSR.2012.12.008.

Ménard, Y., Fu, L. L., Escudier, P., Parisot, F., Perbos, J., Vincent, P., Desai, S., Haines, B., Kunstmann, G., 2003. The Jason-1 Mission special issue: Jason-1 Calibration/Validation. Mar. Geod., 26, 131-146.

Mithcum, G. T., 1998. Monitoring the statibility of satellite altimeters with tide gauges. J. Atmos. Ocean. Tech., 15, 3, 721-730. http://dx.doi.org/10.1175/15200426(1998)015<0721:MTSOSA >2.0.CO;2.

Navarro, G., Huertas, I. E., Costas, E., Flecha, S., Díez-Minguito, M., Caballero, I., López-Rodas, V., Prieto, L., Ruiz, J., 2012. Use of a real-time remote monitoring Network (RTRM) to characterize the Guadalquivir estuary (Spain), Sensors 12, 1398-1421. http://dx.doi.org/10.3390/S120201398.

Oreiro, F., D'Onofrio, E., Grismeyer, W., Fiore, M., Saraceno, M., 2014. Comparison of tide model outputs for the northern region of the Antarctic Peninsula using satellite altimeters and tide gauge data. Polar Science, 8, 10-23, doi: 10.1016/j.polar.2013.12.001.

Passaro, M., Fenoglio-Marc, L., Cipollini, P., 2015. Validation of significant wave height from improved satellite altimetry in the German Bight, IEEE Trans. Geosci. $\quad$ Remote, $\quad 53, \quad 4, \quad 2146-2156$. 
http://dx.doi.org/10.1109/TGRS.2014.2356331.

Peliz, A., Dubert, J., Marchesiello, P., Teles-Machado, A., 2007. Surface circulation in the Gulf of Cadiz: Model and mean flow structure. J. Geophys. Res. 112, C11015, pp. 20. http://dx.doi.org/10.1029/2007jc004159.

Picaut, J., Busalacchi, A. J., McPhaden, M. J., Gourdeau, L., Gonzalez, F. I., Hackert, E. C., 1995. Open ocean validation of TOPEX/POSEIDON sea level data in the western equatorial Pacific. J. Geophys. Res.-Oceans, 100, C12, 25109-25127.

Raney, R. K., 1998. The delay/Doppler radar altimeter, IEEE T. Geosci. Remote, 36, 5, 1578-1588. http://dx.doi.org/10.1109/36.718861.

Ray, C., Martin-Puig, C., Clarizia, M. P., Ruffini, G., Dinardo, S., Gommenginger, C., Benveniste, J., 2015. SAR altimeter backscattered waveform model. IEEE Trans. Geosci. Remote Sens., http://dx.doi.org/10.1109/TGRS.2014.2330423.

Relvas, P., Barton, E. D., 2002. Mesoscale patterns in the Cape San Vicente (Iberian Peninsula) upwelling region. J. Geophys. Res. 107 (C10), 3164. http://dx.doi.org/10.1029/2000JC000456.

Stevenson, R. E., 1977. Huelva Front and Malaga, Spain, Eddy chain as defined by satellite and oceanographic data. Deutsche Hydrographische Zeitschrift 30 (2), $51-53$.

Vignudelli, S., Kostianoy, A., Cipollini, P., Benveniste, J., (eds.), 2011. Coastal Altimetry. Berlin, Germany: Springer-Verlag. http://dx.doi.org/10.1007/978-3642-12796-0.

Vincent, P., Desai, S. D., Dorandeu, J., Ablain, M., Soussi, B., Callahan, P. S., Haines, B. J., 2003. Jason-1 geophysical performance evaluation. Special issue: Jason-1 Calibration/Validation. Mar. Geod., 26, 167-186.

Wessel, P., Smith, W. H. F., 1996. A Global Self-consistent, Hierarchical, Highresolution Shoreline Database. J. Geophys. Res., 101, 8741-8743.

Woodworth, P., Moore, P., Dong, X., Bingley, R., 2004. Mar. Geod., 27, 95-106. http://dx.doi.org/10.1080/01490410490465328. 


\section{FIGURE CAPTIONS}

Figure 1. Study area: the eastern halve of the Gulf of Cadiz (southwestern Iberian Peninsula: Fig. 1.a). The location of the tide gauges: Huelva and Bonanza are marked with black stars in Fig. 1.b. The black dots show a circle around the tide gauges considering a radius of $50 \mathrm{~km}$. Dashed blue lines give the nearest AltiKa track segments to the tide gauges: ascending \#0373 and descending \#0446. Also shown the location of Chipiona city (green dot) and Alcala del Río dam (red dot).

Figure 2. Time series of sea level at 5-minute intervals for Huelva (Fig. 2.a), and Bonanza (tidally corrected with the DTU10 tidal model) (Fig. 2.b) and Bonanza (tidally corrected with the tidal elevations obtained from the harmonic analysis of the tidal constituents) (Fig. 2.c) from August 2010 to December 2014. Atmospheric effects (DAC) and temporal mean were removed as explained in the text.

Figure 3. Absolute difference of along-track consecutives SLA measurements at Huelva station for the closest descending (Fig. 3.a) and ascending (Fig. 3.c) CryoSat-2 passes. The location of the tracks is shown in Fig. 3.b.

Figure 4. Same as Figure 3 for the closest descending (Fig. 4.a) and ascending (Fig. 4.b) CryoSat-2 passes to Bonanza tide gauge. Also included the radargrams with the alongtrack waveforms for descending (Fig. 4.d) and ascending (Fig 4.e).

Figure 5. Position of the time series of the differences between Cryo_SLA and Ins_SLA at different distances to the coast around Huelva (Fig. 5.a) and Bonanza (Fig. 5.b). These time series are the basis for the quantification of rmse in each coastal bands. 
Figure 6. Time series of CryoSat-2 20-Hz SLA (blue line) and 1-Hz SLA (black line) at $1 \mathrm{~km}$ and $20 \mathrm{~km}$ to the coast at Huelva (Fig. 6.a and 6.c) and Bonanza (Fig. 6.b and 6.d). Also included the concomitant time series of in-situ data (red line).

Figure 7. Along-track SLA (01-01-2011) (Fig. 7.a) (absolute orbit \#3884). RGB Modis image three days later with the location of the CryoSat-2 track segment analysed (Fig. 7.b). The daily average of river discharge (in $\mathrm{m}^{3} / \mathrm{s}$ ) in the estuary during this extreme event is in Fig. 7.c.

Figure 8. Along-track SLA at 20-Hz posting rate (Fig. 8.a) and using a running mean of 5 20-Hz measurements for CryoSat-2 absolute orbits \#3884 (black) - 9228 (red) - 14572 (green) and 19916 (blue). The daily mean flow is also shown.

Figure 9. Radargrams with the waveforms corresponding to the time series of SLA measurements used for comparison against Huelva station at $1 \mathrm{~km}$ (Fig. 9.a) and $20 \mathrm{~km}$ (Fig. 9.b) to the coast. 
Table 1. rmse $(\mathrm{cm})$ at Huelva and Bonanza tide gauge stations using the distance to coast as a criterion for CryoSat-2 data selection. The initial number of measurements and percentage of used data is also shown.

\begin{tabular}{c|ccc|cccccc}
\hline \multicolumn{3}{c}{ HUELVA } & \multicolumn{3}{c|}{ BONANZA } & \multicolumn{3}{c}{$\begin{array}{c}\text { BONANZA } \\
\text { (northern cluster) }\end{array}$} \\
\hline $\begin{array}{c}\text { Distance to } \\
\text { land }(\mathbf{k m})\end{array}$ & $\begin{array}{c}\text { rmse } \\
(\mathbf{c m})\end{array}$ & $\begin{array}{c}\text { Initial nb. } \\
\text { of meas. }\end{array}$ & $\begin{array}{c}\text { Final nb. } \\
\text { of meas. } \\
(\%)\end{array}$ & $\begin{array}{c}\text { rmse } \\
(\mathbf{c m})\end{array}$ & $\begin{array}{c}\text { Initial } \\
\text { nb. of } \\
\text { meas. }\end{array}$ & $\begin{array}{c}\text { Final nb. } \\
\text { of meas. } \\
(\%)\end{array}$ & $\begin{array}{c}\text { rmse } \\
(\mathbf{c m})\end{array}$ & $\begin{array}{c}\text { Initial } \\
\text { nb. of } \\
\text { meas. }\end{array}$ & $\begin{array}{c}\text { Final nb. } \\
\text { of meas. } \\
(\%)\end{array}$ \\
\hline $\mathbf{1}$ & 29.3 & 106 & $89(83)$ & 24.7 & 61 & $52(85)$ & 19.1 & 42 & $22(52)$ \\
$\mathbf{3}$ & 11.4 & 106 & $102(96)$ & 16.8 & 57 & $53(92)$ & 20.0 & 38 & $36(94)$ \\
$\mathbf{5}$ & 8.5 & 103 & $99(96)$ & 15.0 & 58 & $51(87)$ & 14.8 & 39 & $36(92)$ \\
$\mathbf{1 0}$ & 7.2 & 95 & $93(97)$ & 13.6 & 55 & $50(90)$ & 12.8 & 36 & $32(88)$ \\
$\mathbf{1 5}$ & 7.3 & 87 & $87(100)$ & 13.5 & 51 & $47(92)$ & 16.5 & 31 & $30(91)$ \\
$\mathbf{2 0}$ & 6.4 & 77 & $76(98)$ & 14.6 & 47 & $44(93)$ & 13.9 & 27 & $25(92)$ \\
\hline
\end{tabular}


Table 2. Same as Table 1 but using the isobath depth as a criterion for Cryosat- 2 data selection.

\begin{tabular}{c|ccc|ccc}
\hline \multicolumn{3}{c}{ HUELVA } & \multicolumn{3}{c}{ BONANZA } \\
\hline $\begin{array}{c}\text { Isobath } \\
\text { depth (m) }\end{array}$ & $\begin{array}{c}\text { rmse } \\
(\mathbf{c m})\end{array}$ & $\begin{array}{c}\text { Initial nb. } \\
\text { of meas. }\end{array}$ & $\begin{array}{c}\text { \% of } \\
\text { used data }\end{array}$ & $\begin{array}{c}\text { rmse } \\
(\mathbf{m})\end{array}$ & $\begin{array}{c}\text { Initial nb. } \\
\text { of meas. }\end{array}$ & $\begin{array}{c}\text { \% of } \\
\text { used data }\end{array}$ \\
\hline $\mathbf{1 0}$ & 16.9 & 105 & 95 & 28.6 & 59 & 83 \\
$\mathbf{2 5}$ & 6.8 & 86 & 98 & 14.3 & 60 & 91 \\
$\mathbf{5 0}$ & 6.8 & 76 & 100 & 13.3 & 54 & 92 \\
$\mathbf{7 5}$ & 6.8 & 70 & 98 & 14.5 & 46 & 91 \\
\hline
\end{tabular}


Table 3. rmse $(\mathrm{cm})$ at Huelva and Bonanza tide gauge stations using different posting rates.

\begin{tabular}{|c|c|c|c|c|c|c|c|c|c|c|}
\hline \multirow[b]{2}{*}{$\begin{array}{l}\text { Distance to } \\
\text { land }(\mathbf{k m})\end{array}$} & \multicolumn{5}{|c|}{ HUELVA } & \multicolumn{5}{|c|}{ BONANZA } \\
\hline & $20 \mathrm{~Hz}$ & $\begin{array}{c}10 \mathrm{~Hz} \\
(2)^{1}\end{array}$ & $\begin{array}{c}5 \mathrm{~Hz} \\
(4)^{1}\end{array}$ & $\begin{array}{l}2 \mathrm{~Hz} \\
(10)^{1}\end{array}$ & $\begin{array}{l}1 \mathrm{~Hz} \\
(20)^{1}\end{array}$ & $20 \mathrm{~Hz}$ & $\begin{array}{c}10 \mathrm{~Hz} \\
(2)^{1}\end{array}$ & $\begin{array}{c}5 \mathrm{~Hz} \\
(4)^{1}\end{array}$ & $\begin{array}{l}2 \mathrm{~Hz} \\
(10)^{1}\end{array}$ & $\begin{array}{l}1 \mathrm{~Hz} \\
(20)^{1}\end{array}$ \\
\hline 1 & 29.3 & 26.7 & 24.3 & 13.3 & 11.7 & 24.7 & 30.0 & 29.7 & 29.7 & 26.5 \\
\hline 3 & 11.4 & 11.4 & 10.8 & 10.1 & 9.3 & 16.8 & 16.4 & 16.2 & 16.2 & 16.1 \\
\hline 5 & 8.5 & 8.2 & 8.9 & 7.9 & 7.9 & 15.0 & 14.8 & 16.4 & 15.2 & 14.9 \\
\hline 10 & 7.2 & 6.6 & 6.2 & 5.9 & 5.9 & 13.6 & 13.6 & 13.1 & 12.6 & 12.9 \\
\hline 15 & 7.3 & 6.5 & 5.9 & 5.1 & 4.9 & 13.5 & 13.2 & 12.5 & 12.9 & 13.2 \\
\hline 20 & 6.4 & 5.8 & 5.7 & 4.7 & 4.6 & 14.6 & 14.4 & 14.6 & 12.9 & 13.1 \\
\hline
\end{tabular}

1 numbers of consecutive $20-\mathrm{Hz}$ along-track SLAs used for averaging 
Table 4. rmse $(\mathrm{cm})$ at Huelva and Bonanza tide gauge stations from CryoSat-2 and AltiKa at a 20-Hz posting rate.

\begin{tabular}{|c|c|c|c|c|c|c|c|c|}
\hline \multirow[b]{3}{*}{$\begin{array}{l}\text { Distance to } \\
\text { land }(\mathbf{k m})\end{array}$} & \multicolumn{4}{|c|}{ HUELVA } & \multicolumn{4}{|c|}{ BONANZA } \\
\hline & \multicolumn{2}{|c|}{ CryoSat-2 (20 Hz) } & \multicolumn{2}{|c|}{$\begin{array}{c}\text { AltiKa }(20 \mathrm{~Hz}) \\
\text { Track \#0373 }\end{array}$} & \multicolumn{2}{|c|}{ CryoSat-2 $(20 \mathrm{~Hz})$} & \multicolumn{2}{|c|}{$\begin{array}{c}\text { AltiKa }(20 \mathrm{~Hz}) \\
\text { Track \#0446 }\end{array}$} \\
\hline & $\begin{array}{l}r m s e \\
(\mathrm{~cm})\end{array}$ & $\begin{array}{c}\text { \% of used } \\
\text { data }\end{array}$ & $\begin{array}{l}r m s \\
(\mathrm{~cm}\end{array}$ & $\begin{array}{c}\text { \% of used } \\
\text { data }\end{array}$ & $\begin{array}{l}r m s e \\
(\mathrm{~cm})\end{array}$ & $\begin{array}{c}\text { \% of used } \\
\text { data }\end{array}$ & $\begin{array}{l}r m s e \\
(\mathrm{~cm})\end{array}$ & $\begin{array}{c}\text { \% of used } \\
\text { data }\end{array}$ \\
\hline 1 & 29.3 & 83 & 57. & 28 & 24.7 & 61 & $\varnothing$ & 0 \\
\hline 3 & 11.4 & 96 & 44.5 & 61 & 16.8 & 57 & $\varnothing$ & 0 \\
\hline 5 & 8.5 & 96 & 35. & 71 & 15.0 & 58 & $\varnothing$ & 0 \\
\hline 10 & 7.2 & 97 & 5.3 & 80 & 13.6 & 55 & $\varnothing$ & 0 \\
\hline 15 & 7.3 & 100 & 6.4 & 80 & 13.5 & 51 & 17.5 & 85 \\
\hline 20 & 6.4 & 98 & 5.0 & 80 & 14.6 & 47 & 17.7 & 85 \\
\hline
\end{tabular}


FIGURE 1
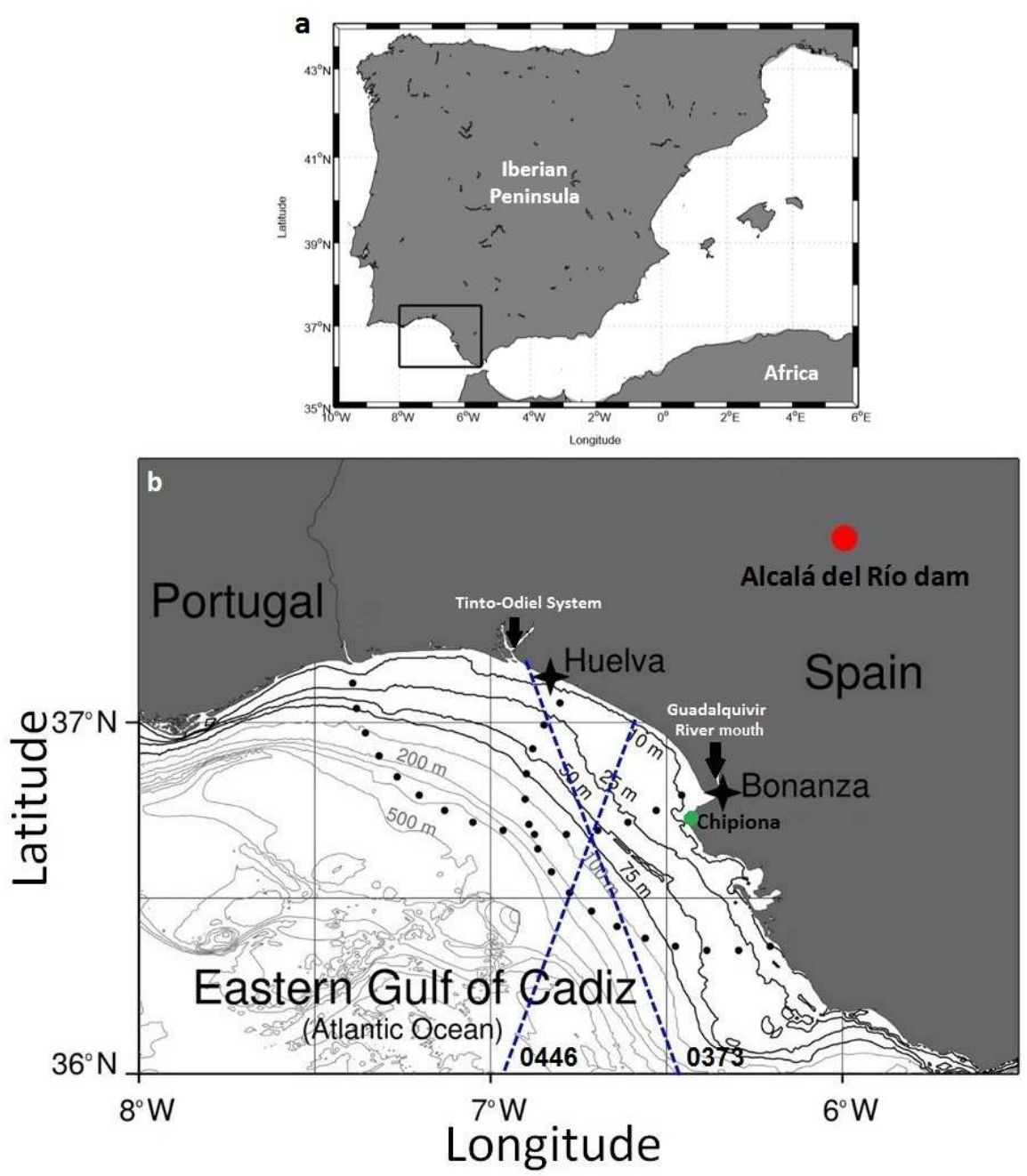

Figure 1. Study area: the eastern halve of the Gulf of Cadiz (southwestern Iberian Peninsula: Fig. 1.a). The location of the tide gauges: Huelva and Bonanza are marked with black stars in Fig. 1.b. The black dots show a circle around the tide gauges considering a radius of $50 \mathrm{~km}$. Dashed blue lines give the nearest AltiKa track segments to the tide gauges: ascending \#0373 and descending \#0446. Also shown the location of Chipiona city (green dot) and Alcala del Río dam (red dot). 
FIGURE 2

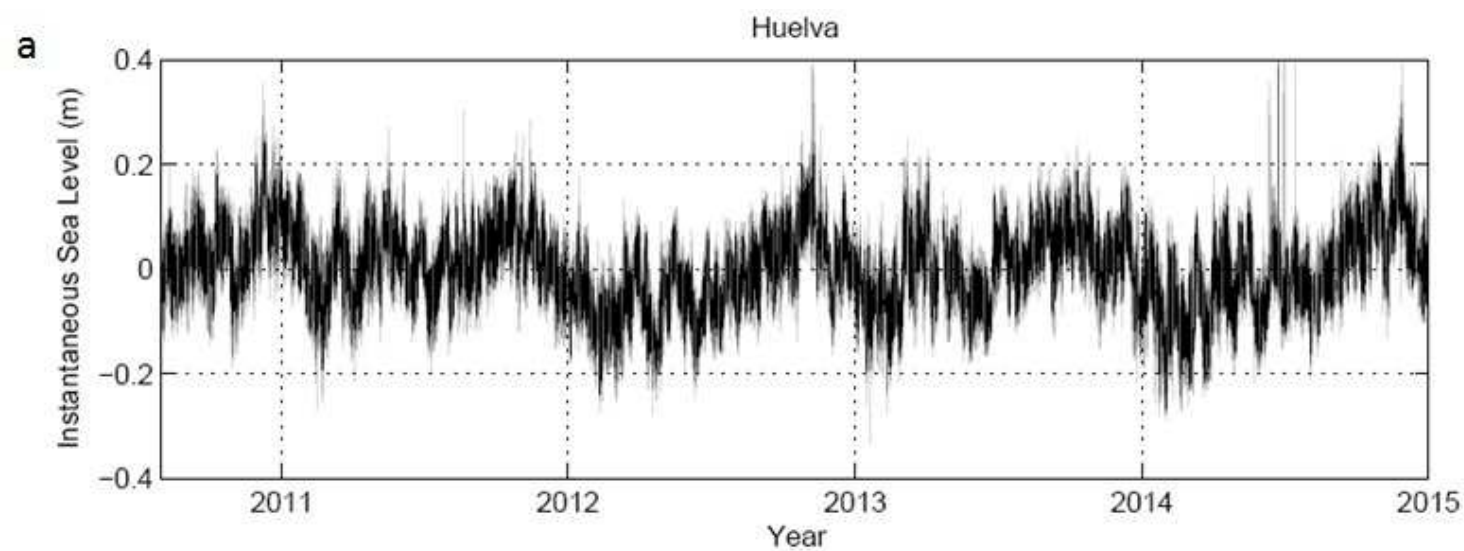

b

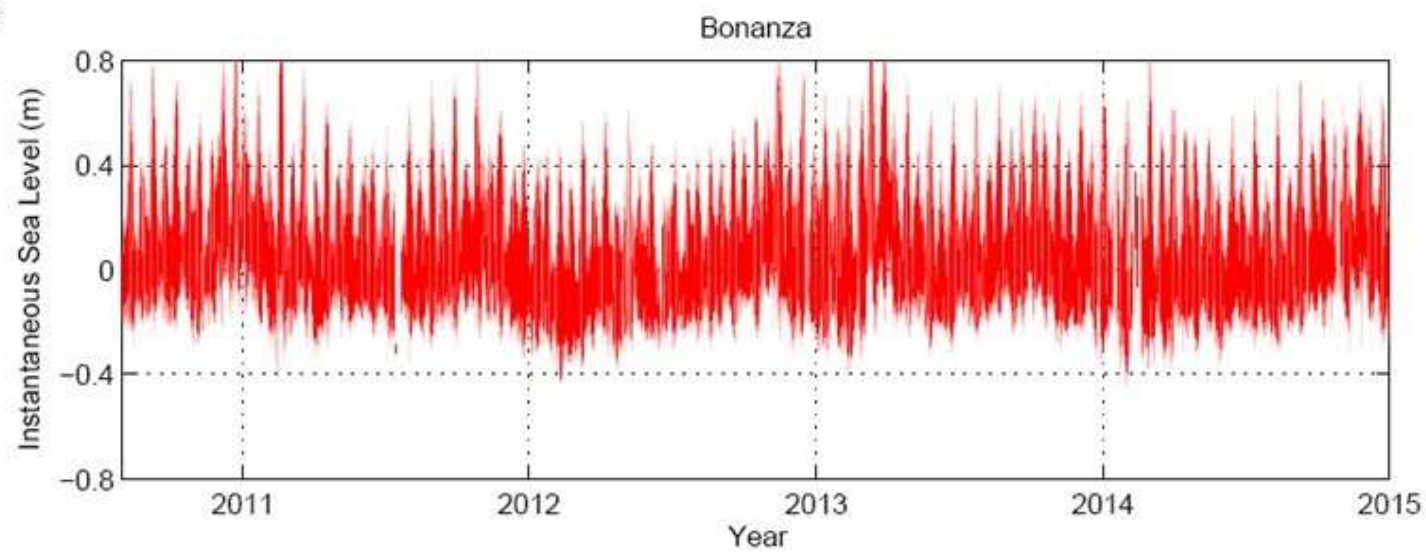

C

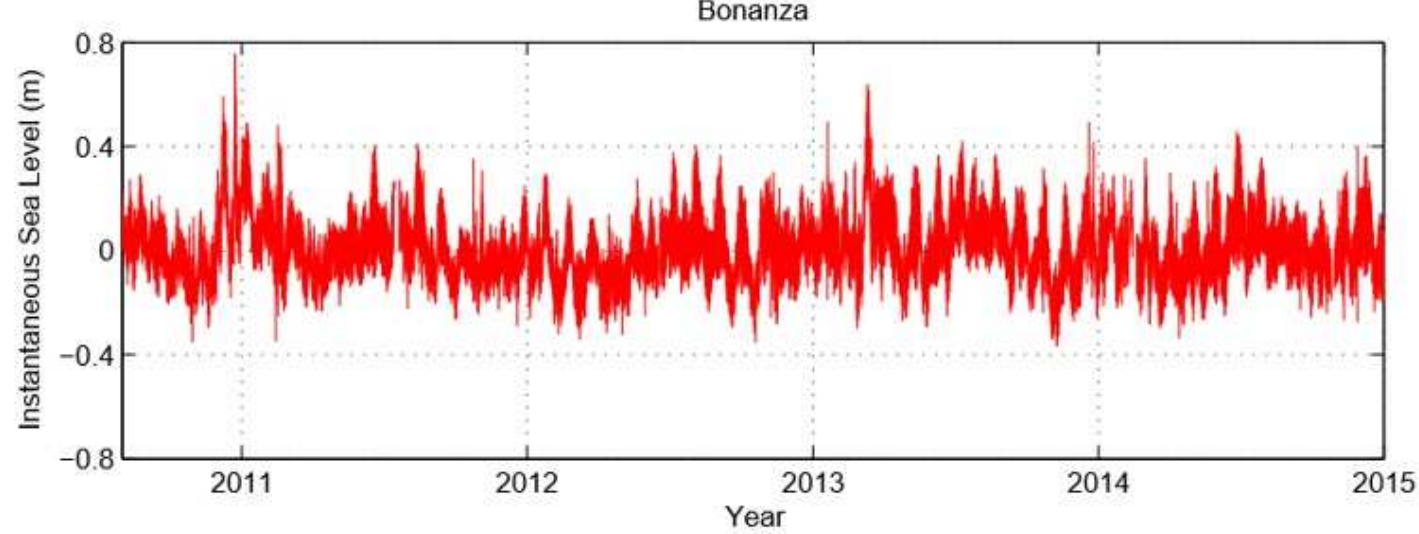

Figure 2. Time series of sea level at 5-minute intervals for Huelva (Fig. 2.a), Bonanza (tidally corrected with the DTU10 tidal model) (Fig. 2.b) and Bonanza (tidally corrected with the tidal elevations obtained from the harmonic analysis of the tidal constituents)

(Fig. 2.c) from August 2010 to December 2014. Atmospheric effects (DAC) and temporal mean were removed as explained in the text. 
FIGURE 3

a

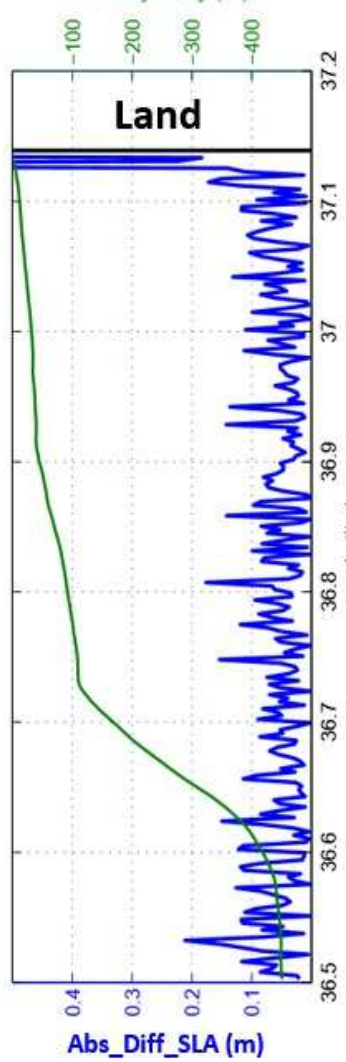

b

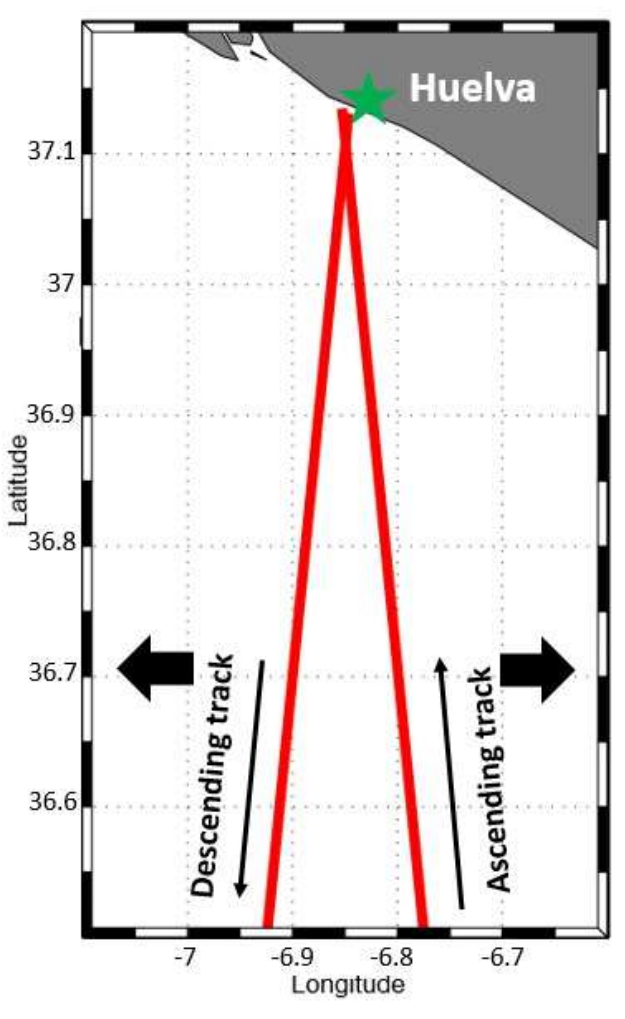

C Bathymetry (m)

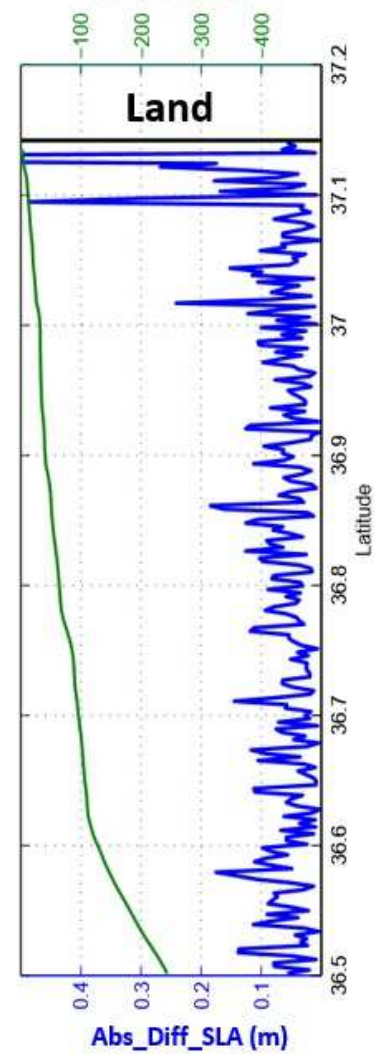

Figure 3. Absolute difference of along-track consecutives SLA measurements at Huelva station for the closest descending (Fig. 3.a) and ascending (Fig. 3.c) CryoSat-2 passes. The location of the tracks is shown in Fig. 3.b. 
FIGURE 4

a

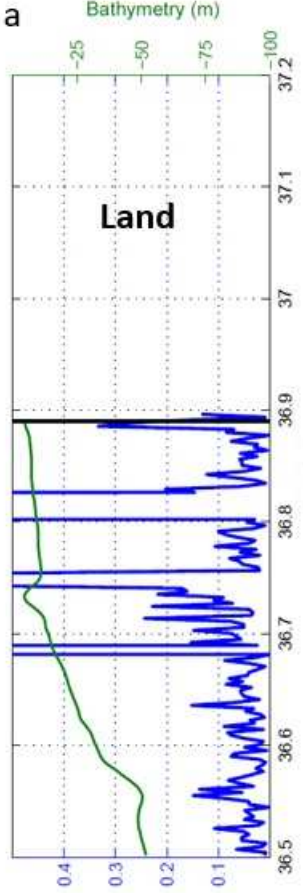

Abs_Diff_SLA (m)

d

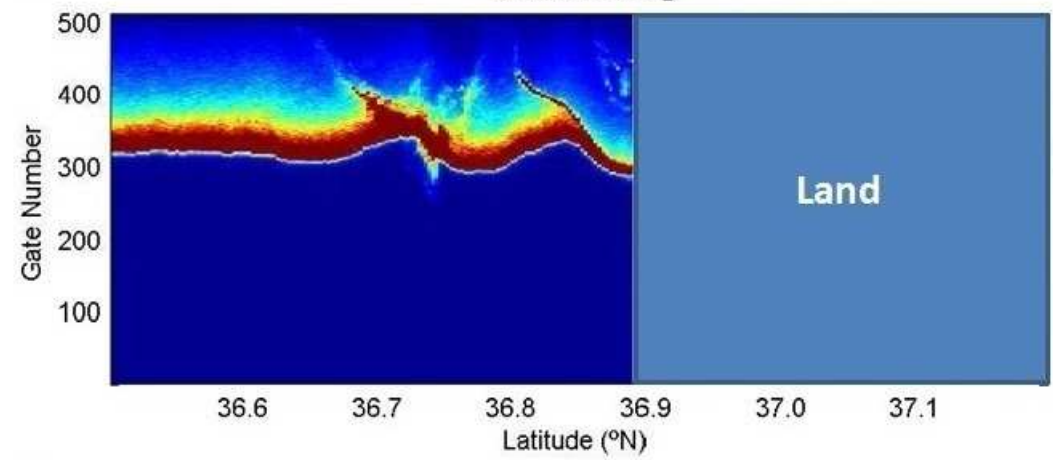

e

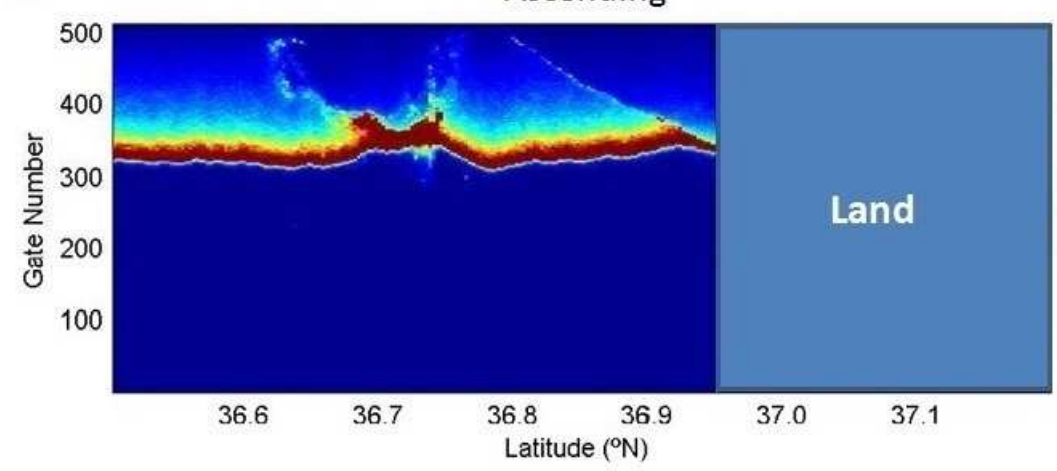

Ascending
C Bathymetry (m)

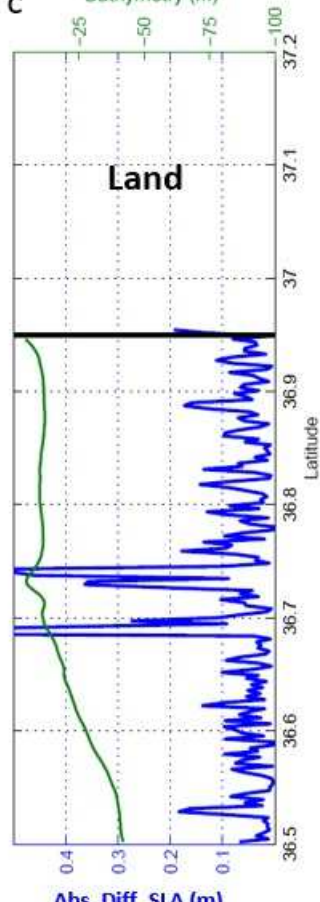

Abs_Diff_SLA (m)

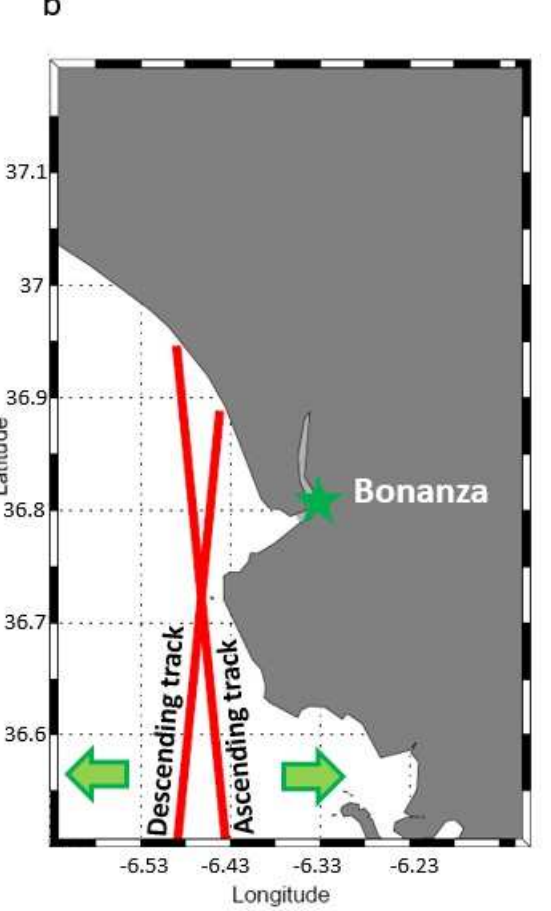

\section{Descending}

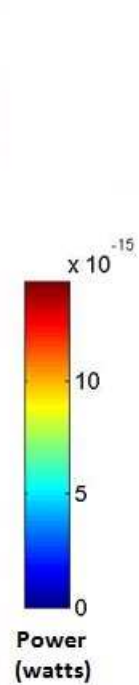

Figure 4. Same as Figure 3 for the closest descending (Fig. 4.a) and ascending (Fig. 4.b) CryoSat-2 passes to Bonanza tide gauge. Also included the radargrams with the alongtrack waveforms for descending (Fig. 4.d) and ascending (Fig 4.e). 


\section{FIGURE 5}
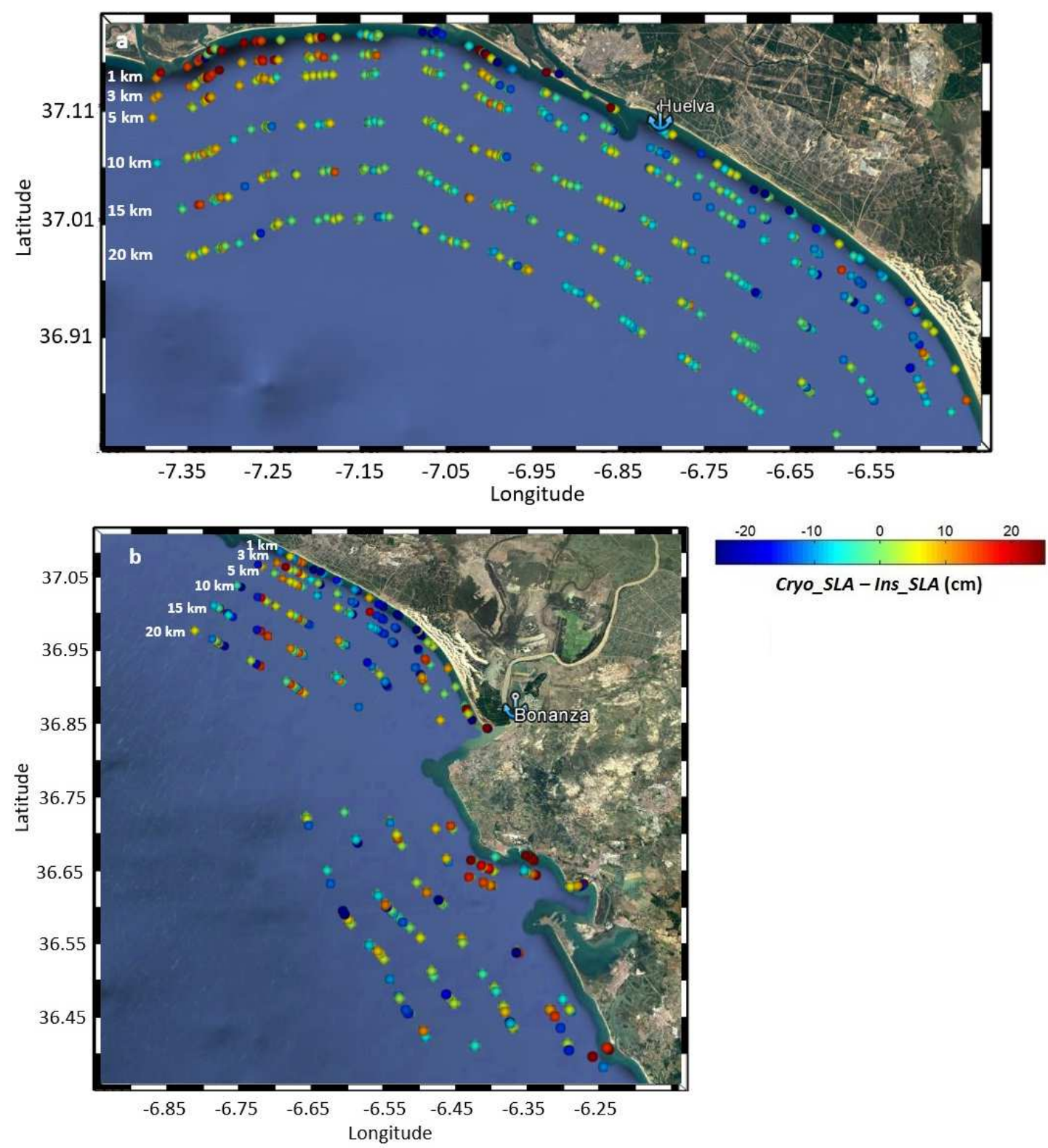

Cryo_SLA - Ins_SLA (cm)

Figure 5. Position of the time series of the differences between Cryo_SLA and Ins_SLA at different distances to the coast around Huelva (Fig. 5.a) and Bonanza (Fig. 5.b). These time series are the basis for the quantification of rmse in each coastal bands. 
FIGURE 6
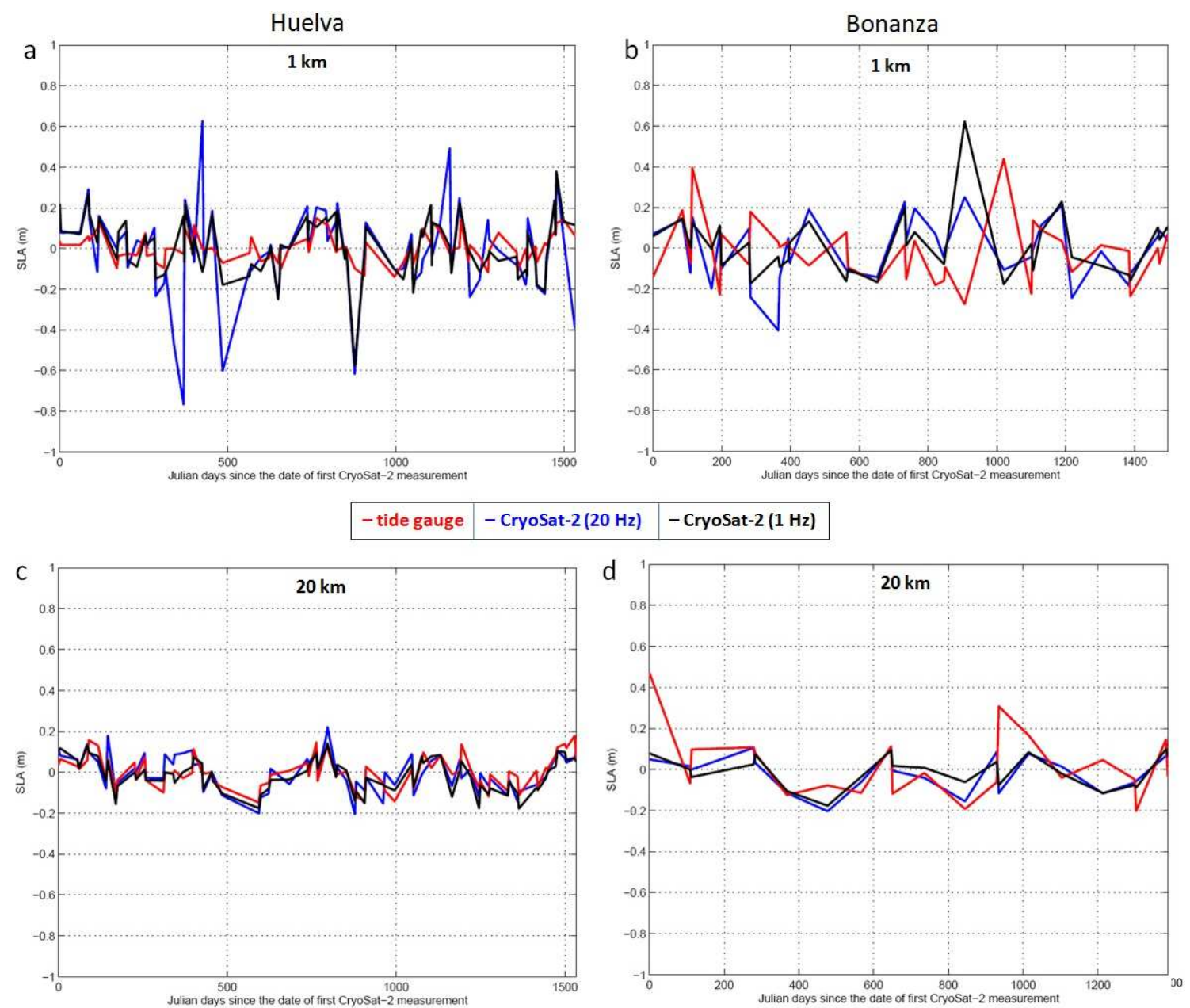

Figure 6. Time series of CryoSat-2 20-Hz SLA (blue line) and 1-Hz SLA (black line) at $1 \mathrm{~km}$ and $20 \mathrm{~km}$ to the coast at Huelva (Fig. 6.a and 6.c) and Bonanza (Fig. 6.b and 6.d). Also included the concomitant time series of in-situ data (red line). 
FIGURE 7
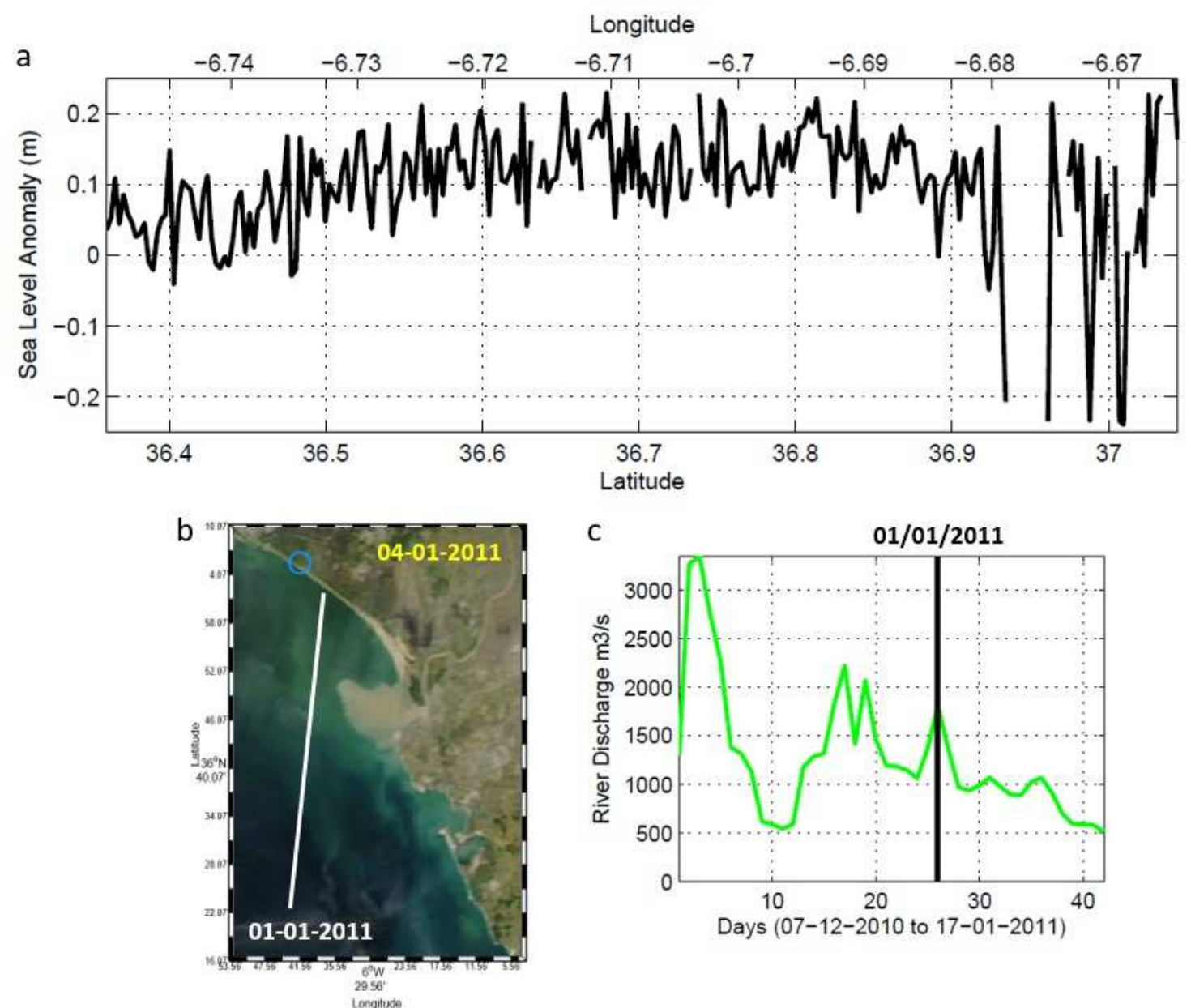

Figure 7. Along-track SLA (01-01-2011) (Fig. 7.a) (absolute orbit \#3884). RGB Modis image three days later with the location of the CryoSat-2 track segment analysed (Fig. 7.b). The daily average of river discharge (in $\mathrm{m}^{3} / \mathrm{s}$ ) in the estuary during this extreme event is in Fig. 7.c. 


\section{FIGURE 8}
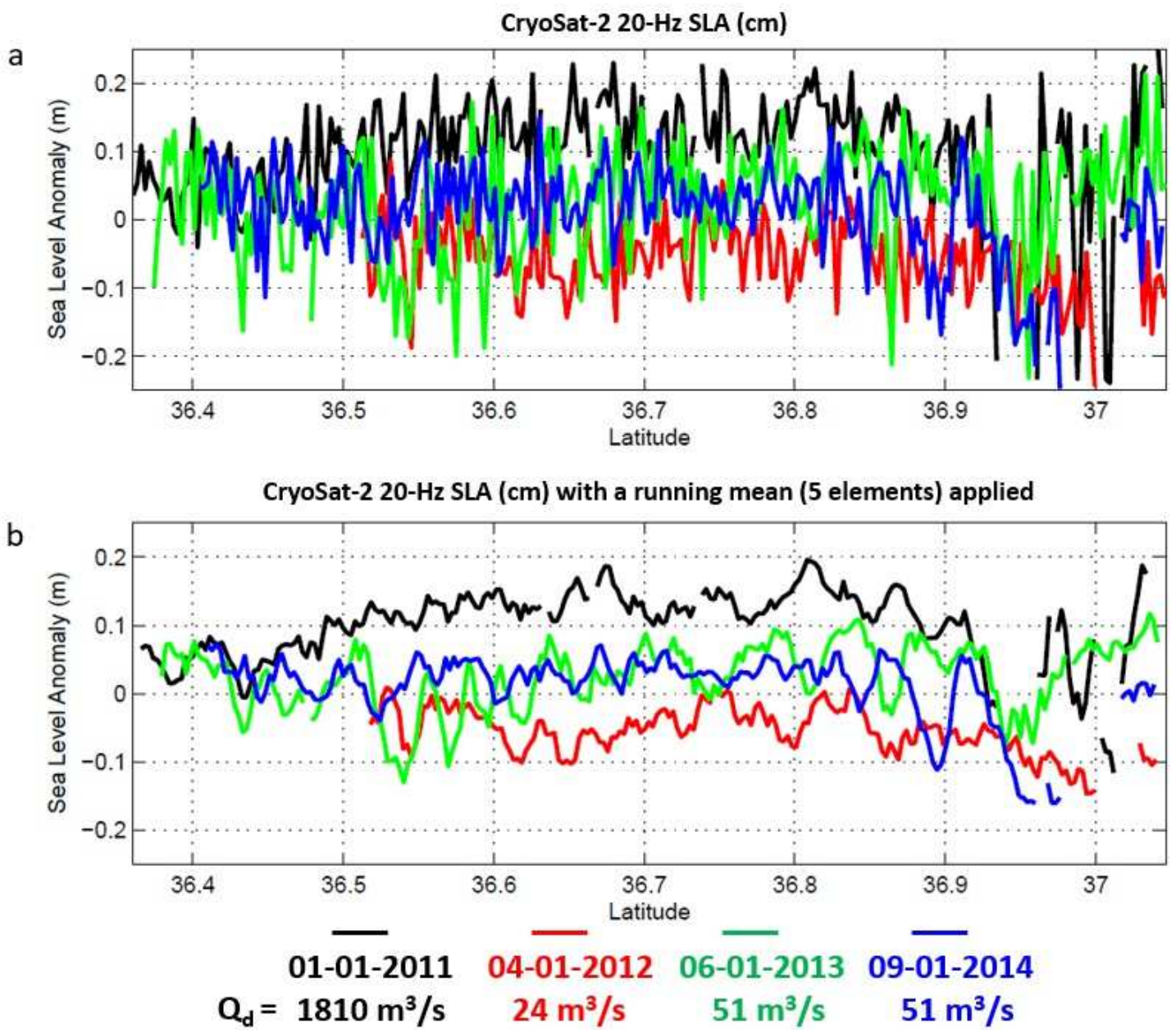

Figure 8. Along-track SLA at $20-\mathrm{Hz}$ posting rate (Fig. 8.a) and using a running mean of 5 20-Hz measurements for CryoSat-2 absolute orbits \#3884 (black) - 9228 (red) - 14572 (green) and 19916 (blue). The daily mean flow is also shown. 
FIGURE 9

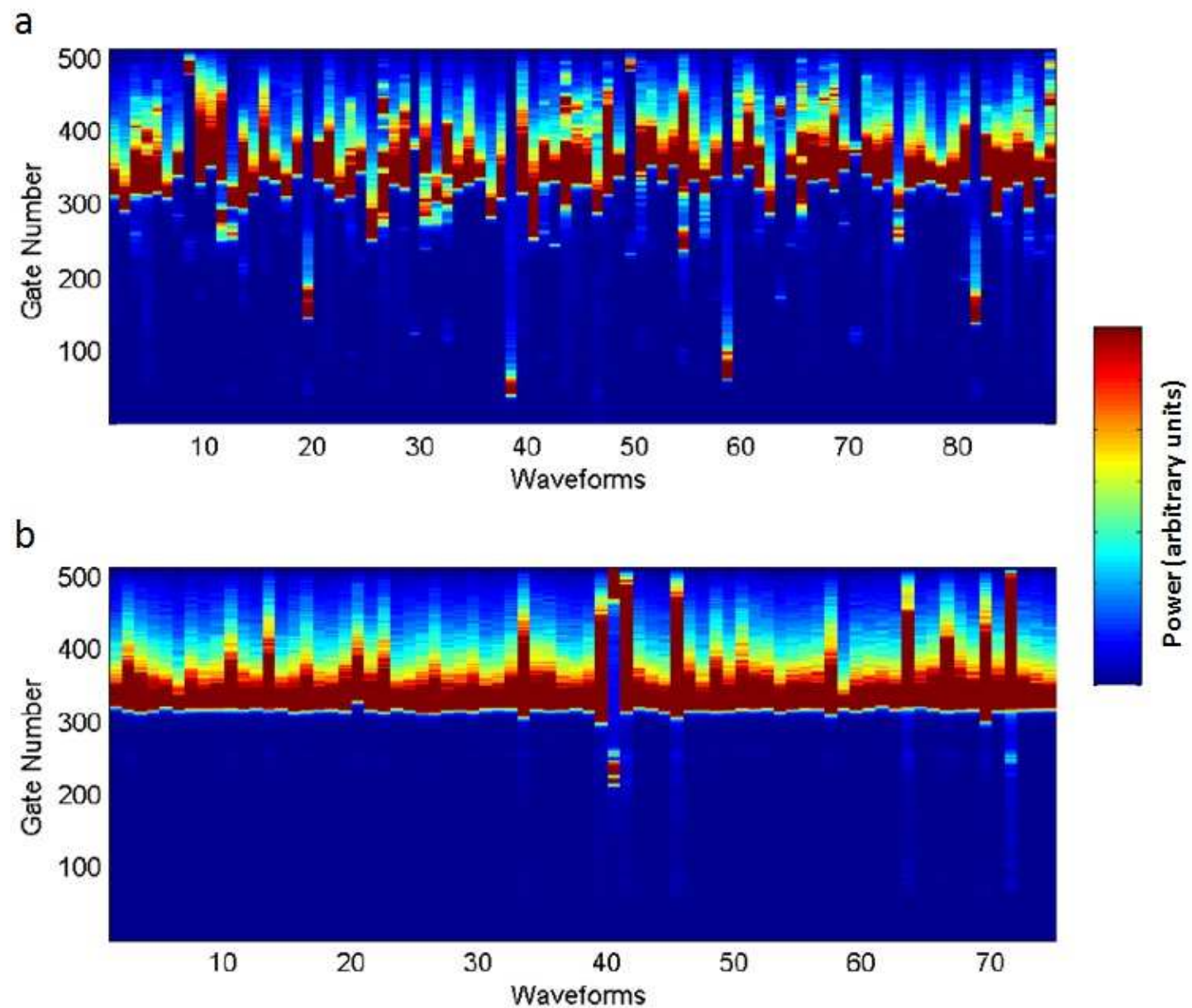

Figure 9. Radargrams with the waveforms corresponding to the time series of SLA measurements used for comparison against Huelva station at $1 \mathrm{~km}$ (Fig. 9.a) and $20 \mathrm{~km}$ (Fig. 9.b) to the coast. 